\title{
Quantifying wetland methane emissions with process-based models of different complexities
}

\author{
J. Tang ${ }^{1,2}$, Q. Zhuang ${ }^{1,2,3}$, R. D. Shannon ${ }^{4}$, and J. R. White ${ }^{5}$ \\ ${ }^{1}$ Dept. of Earth and Atmospheric Sciences, Purdue University, West Lafayette, Indiana, USA \\ ${ }^{2}$ Purdue Climate Change Research Center, West Lafayette, Indiana, USA \\ ${ }^{3}$ Department of Agronomy, Purdue University, West Lafayette, Indiana, USA \\ ${ }^{4}$ Department of Agricultural \& Biological Engineering, Pennsylvania State University, University Park, Pennsylvania, USA \\ ${ }^{5}$ Biogeochemical Laboratories \& Center for Research in Environmental Sciences, Indiana Univ., Bloomington, Indiana, USA
}

Received: 2 July 2010 - Published in Biogeosciences Discuss.: 16 August 2010

Revised: 10 November 2010 - Accepted: 13 November 2010 - Published: 25 November 2010

\begin{abstract}
Bubbling is an important pathway of methane emissions from wetland ecosystems. However the concentration-based threshold function approach in current biogeochemistry models of methane is not sufficient to represent the complex ebullition process. Here we revise an extant process-based biogeochemistry model, the Terrestrial Ecosystem Model into a multi-substance model $\left(\mathrm{CH}_{4}, \mathrm{O}_{2}\right.$, $\mathrm{CO}_{2}$ and $\mathrm{N}_{2}$ ) to simulate methane production, oxidation, and transport (particularly ebullition) with different model complexities. When ebullition is modeled with a concentrationbased threshold function and if the inhibition effect of oxygen on methane production and the competition for oxygen between methanotrophy and heterotrophic respiration are retained, the model becomes a two-substance system. Ignoring the role of oxygen, while still modeling ebullition with a concentration-based threshold function, reduces the model to a one-substance system. These models were tested through a group of sensitivity analyses using data from two temperate peatland sites in Michigan. We demonstrate that only the four-substance model with a pressure-based ebullition algorithm is able to capture the episodic emissions induced by a sudden decrease in atmospheric pressure or by a sudden drop in water table. All models captured the retardation effect on methane efflux from an increase in surface standing water which results from the inhibition of diffusion and the increase in rhizospheric oxidation. We conclude that to
\end{abstract}

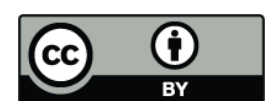

Correspondence to: J. Tang (tang16@purdue.edu) more accurately account for the effects of atmospheric pressure dynamics and standing water on methane effluxes, the multi-substance model with a pressure-based ebullition algorithm should be used in the future to quantify global wetland $\mathrm{CH}_{4}$ emissions. Further, to more accurately simulate the pore water gas concentrations and different pathways of methane transport, an exponential root distribution function should be used and the phase-related parameters should be treated as temperature dependent.

\section{Introduction}

Methane $\left(\mathrm{CH}_{4}\right)$ emitted from natural wetlandsis a significant component of its atmospheric budget. Biogeochemistry and atmospheric inversion models estimate the total wetland emissions to be $100-230 \mathrm{TgCH}_{4} \mathrm{y}^{-1}$, around $25 \%$ of the global emissions into the atmosphere under the current climate condition (Denman et al., 2007). Inverse modeling estimates the strengths of various $\mathrm{CH}_{4}$ sources and sinks by comparing the model simulated $\mathrm{CH}_{4}$ concentrations to spatially discrete and temporally continuous observations of the atmospheric $\mathrm{CH}_{4}$ concentrations (e.g. Houweling et al., 1999). Since all sources/sinks are treated simultaneously in the inversion, the total $\mathrm{CH}_{4}$ emissions into the atmosphere can be well constrained. However, there are various limitations including the sparse in-situ observation networks of atmospheric $\mathrm{CH}_{4}$ and unclear sources and sinks due to insufficient understanding of the biogeochemical processes. As a result, the estimates for different sources/sinks from inverse

Published by Copernicus Publications on behalf of the European Geosciences Union. 
modeling are usually subject to great uncertainties. Processbased models integrate and extrapolate the knowledge from field studies at limited sites to regional and global scales. Because of sparse site-level information and inadequate representation of $\mathrm{CH}_{4}$ processes in these models, the uncertainties in the quantification from biogeochemical modeling are also substantial (e.g., Walter et al., 2001; Zhuang et al., 2004, 2009; Denman et al., 2007).

To date, a group of process-based models with different complexities have been developed to quantify the spatial and temporal patterns of wetland $\mathrm{CH}_{4}$ emissions. Among them, the one-substance models are widely used (e.g., Walter and Heimann, 2000; Zhuang et al., 2004; van Huissteden et al., 2006). These models focus on $\mathrm{CH}_{4}$ only, and assume that methanogenesis and methanotrophy occur in anoxic and oxic zones, respectively, which are spatially separated by the position of water table. In contrast, the two-substance model considers $\mathrm{CH}_{4}$ and $\mathrm{O}_{2}$ simultaneously, and the methanogenesis and methanotrophy occur according to the status of both gases in soils (e.g., Arah and Kirk, 2000). This is accomplished by introducing the inhibition effect of $\mathrm{O}_{2}$ on $\mathrm{CH}_{4}$ production and the competition for $\mathrm{O}_{2}$ between heterotrophic respiration and methanotrophy. As such, $\mathrm{CH}_{4}$ oxidation and heterotrophic respiration dominate in the oxic zone while $\mathrm{CH}_{4}$ production dominates in the anoxic zone. The twosubstance models have been used in modeling $\mathrm{CH}_{4}$ emissions from rice paddies (Matthews et al., 2000), and showed reasonable results compared with field measurements. Other existing models are conceptually of either one-substance or two-substance model structure (e.g., Potter, 1997; Zhang et al., 2002).

In biogeochemistry models, three pathways for gas transport are considered: (1) molecular diffusion, (2) plant-aided transport and (3) ebullition, though some models lump the three pathways together (e.g., Cao et al., 1995; Sass et al., 2000; Zhang et al., 2002). Ebullition, if considered explicitly, is often modeled as a threshold phenomenon using the Heaviside function with some universally prescribed threshold concentration of the dissolved gases (e.g., Walter and Heimann, 2000; Matthews et al., 2000). Field and analytical studies suggest such a simple algorithm does not fully represent the physical processes of ebullition (Bazhin, 2001, 2004; Baird et al., 2004; Tokida et al., 2005, 2007). Specifically, several factors have not been considered in the concentrationbased threshold function algorithms: (1) the composition of the bubbles affected by multiple substances such as $\mathrm{CO}_{2}$ and $\mathrm{N}_{2}$; (2) the effects of the hydrostacy affected by water table dynamics and atmospheric pressure variation (Bazhin, 2001; Tokida et al., 2005, 2007) and (3) the ebullition threshold defined in terms of gas volumes is fuzzy rather than deterministically predictable because of possible re-dissolution and gas entrapping, during the course of ebullition (Martens and Klump, 1980; Kellner et al., 2006; Coulthard et al., 2009).

In this study, we revise the $\mathrm{CH}_{4}$ module in a biogeochemistry model, the Terrestrial Ecosystem Model (TEM)
(Zhuang et al., 2004) by incorporating the effects of multiple substances in a soil profile and a probabilistic pressurebased algorithm for ebullition. We apply the revised model to two temperate peatland ecosystems to demonstrate the importance of considering the effects of multiple substances in soils on episodic emissions during atmospheric pressure changes (Mattson and Likens, 1990). We also demonstrate the retardation effects of increases in standing water depth on $\mathrm{CH}_{4}$ effluxes when different model complexities are assumed (Jauhiainen et al., 2005; Zona et al., 2009).

\section{Methods}

\subsection{Overview}

We developed a four-substance $\mathrm{CH}_{4}$ module within a biogeochemistry model, the Terrestrial Ecosystem Model (Zhuang et al., 2004). The model was calibrated and applied to data from two temperate peatland sites in Michigan to demonstrate the capabilities of models with different complexities in simulating $\mathrm{CH}_{4}$ effluxes. A group of sensitivity analyses were conducted to assess the need for a four-substance model with an improved ebullition algorithm.

\subsection{The revised $\mathrm{CH}_{4}$ module}

The governing equation for a non-adsorbed substrate in a soil column (Fig. 1) is:

$$
\begin{aligned}
\frac{\partial y}{\partial t}= & \frac{\partial}{\partial z}\left(D \frac{\partial y}{\partial z}\right)+P-Q-E-R \\
& \min \left(0, z_{\mathrm{wt}}\right) \leq z \leq Z_{\text {soil }}
\end{aligned}
$$

where

$$
\begin{array}{ll}
\frac{\partial}{\partial z}\left(D \frac{\partial y}{\partial z}\right): & \text { Diffusion } \\
P: & \text { Production } \\
Q: & \text { Consumption } \\
E: & \text { Ebullition } \\
R: & \text { Plant transport }
\end{array}
$$

and $z_{\mathrm{wt}}$ (unit: $\mathrm{m}$ ) is the water table depth, being negative when it is above the soil surface. For substance $i$, the bulk concentration $y_{i}$ (unit: $\mathrm{mol} \mathrm{m}^{-3}$ ) is related to its aqueous concentration $y_{i, \mathrm{w}}$ (unit: $\mathrm{mol} \mathrm{m}^{-3}$ water) and gaseous concentration $y_{i, \mathrm{a}}$ (unit: $\mathrm{mol} \mathrm{m}^{-3}$ air) through

$y_{i}=\epsilon y_{i, \mathrm{a}}+\theta y_{i, \mathrm{w}}=\left(\epsilon+\theta \alpha_{i}\right) y_{i, \mathrm{a}}$

where $\epsilon(z, t)$ (unit: $\mathrm{m}^{3}$ air $\mathrm{m}^{-3}$ soil) is air-filled porosity, $\alpha_{i}$ is the Bunsen coefficient for gas $i$ (see Appendix A for its calculation) and $\theta(z, t)$ (unit: $\mathrm{m}^{3}$ water $\mathrm{m}^{-3}$ soil) is the volumetric soil moisture.

The boundary conditions for Eq. (1) are

$y_{0}(t)=y(0, t)$ for volatiles 


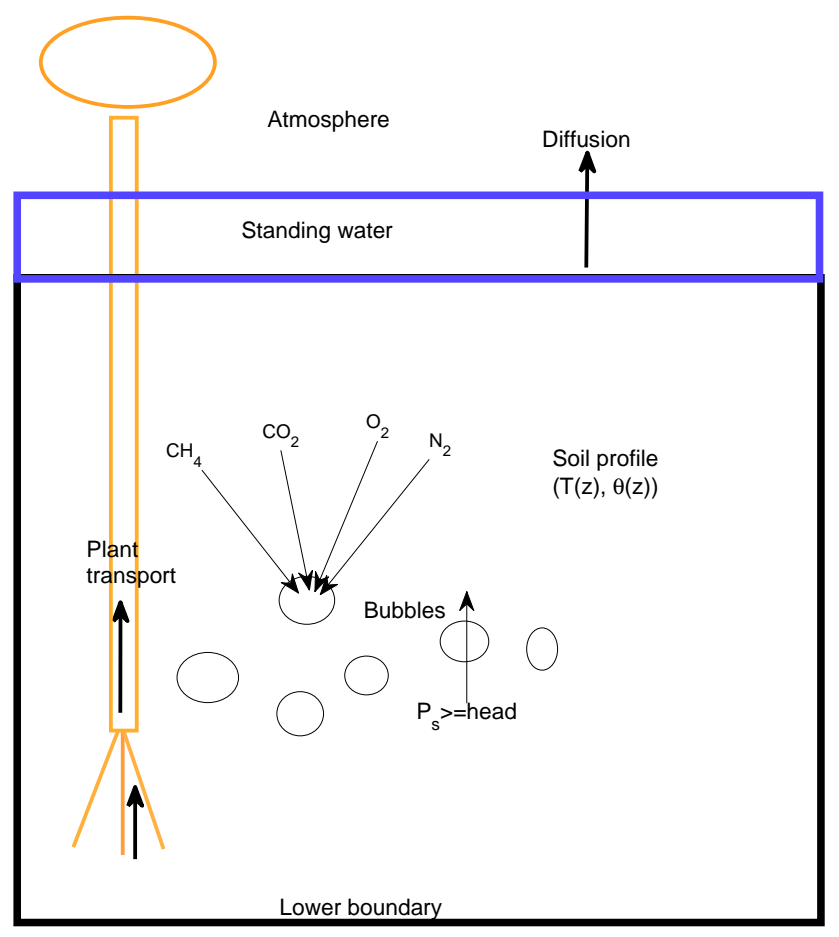

Fig. 1. Diagram showing the three major gas-transport pathways involved in the multi-substance $\mathrm{CH}_{4}$ model. See text for details about the calculations.

$\frac{\partial y}{\partial z}=0$ for nonvolatiles

at the upper boundary $\left(z=\min \left(0, z_{\mathrm{wt}}\right)\right)$ and

$$
\frac{\partial y}{\partial z}=0
$$

at the lower boundary $\left(z=Z_{\text {soil }}\right)$ for all substrates.

\subsubsection{Chemistry involved in methane production and consumption}

In wetland ecosystems, $\mathrm{CH}_{4}$ is produced primarily through methanogenesis

$\mathrm{CH}_{2} \mathrm{O}+\mathrm{CH}_{2} \mathrm{O} \rightarrow \mathrm{CO}_{2}+\mathrm{CH}_{4}$

and consumed through methanotrophy

$\mathrm{CH}_{4}+2 \mathrm{O}_{2} \rightarrow \mathrm{CO}_{2}+2 \mathrm{H}_{2} \mathrm{O}$

Methanogenesis can proceed in either of the two pathways (Conrad, 1989), i.e. $\mathrm{CO}_{2}+4 \mathrm{H}_{2} \rightarrow \mathrm{CH}_{4}+2 \mathrm{H}_{2} \mathrm{O}$, or $\mathrm{CH}_{3} \mathrm{COO}^{-}+\mathrm{H}^{+} \rightarrow \mathrm{CO}_{2}+\mathrm{CH}_{4}$, both of which can equivalently be reduced to Eq. (7). Though there are other pathways, e.g. $\mathrm{HCOO}^{-}+\frac{1}{2} \mathrm{H}_{2} \mathrm{O}+\frac{1}{4} \mathrm{CO}_{2} \rightarrow \frac{1}{4} \mathrm{CH}_{4}+\mathrm{HCO}_{3}^{-}$, and $\mathrm{CH}_{3} \mathrm{OH} \rightarrow \frac{3}{4} \mathrm{CH}_{4}+\frac{1}{2} \mathrm{H}_{2} \mathrm{O}+\frac{1}{4} \mathrm{CO}_{2}$, leading to $\mathrm{CH}_{4}$ production, we assumed they are minor as indicated in previous studies (Conrad, 1989). If one makes the assumption that dissolved oxygen is negligible in the aqueous phase, then the water table serves as a boundary in the soil between the oxic zone above the water table and the anoxic zone below the water table. Consequently, the equation to solve for the wetland $\mathrm{CH}_{4}$ profile in a soil column is reduced to a system of a single substance, i.e. $\mathrm{CH}_{4}$, only. Such was adopted in Walter et al. (2001) and Zhuang et al. (2004), where the bubbling was modeled as a switch-on and -off process with a prescribed threshold $\mathrm{CH}_{4}$ concentration, $\mathrm{CH}_{4, \max }$ (unit: mol $\mathrm{m}^{-3}$ water).

If one considers the competition for $\mathrm{O}_{2}$ in $\mathrm{CH}_{4}$ oxidation and respiration processes, a third stoichiometry is involved:

$\mathrm{CH}_{2} \mathrm{O}+\mathrm{O}_{2} \rightarrow \mathrm{CO}_{2}+\mathrm{H}_{2} \mathrm{O}$

With such, we obtained a two-substance model considering both $\mathrm{CH}_{4}$ and $\mathrm{O}_{2}$ in a soil profile. Characterization of the aerobic and anaerobic zone in a soil column by the water table in the one-substance system is now revised by introducing the inhibition of $\mathrm{O}_{2}$ on $\mathrm{CH}_{4}$ production

$P_{\mathrm{CH}_{4}}=P_{\mathrm{CH}_{4}}^{*} /\left(1+\eta y_{\mathrm{O}_{2}, \mathrm{w}}\right)$

where $P_{\mathrm{CH}_{4}}^{*}$ (unit: $\mathrm{molm}^{-3} \mathrm{~s}^{-1}$ ) is the maximum $\mathrm{CH}_{4}$ production potential when the environment is completely anoxic, and $\eta$ (unit: $\mathrm{m}^{3}$ water $\mathrm{mol}^{-1}$ ) is a parameter representing the sensitivity of methanogenesis to the concentration of dissolved oxygen $y_{\mathrm{O}_{2}, \mathrm{w}}$ in pore water. A value of $400 \mathrm{~m}^{3}$ water $\mathrm{mol}^{-1}$ from Arah and Kirk (2000) was used for $\eta . P_{\mathrm{CH}_{4}}^{*}$ is defined in Appendix B.

Accordingly, the methanotrophy is restricted by the availability of $\mathrm{O}_{2}$ as

$Q_{\mathrm{CH}_{4}}=Q_{\mathrm{CH}_{4}}^{*} \frac{y_{\mathrm{CH}_{4}, \mathrm{w}}}{k_{\mathrm{CH}_{4}}+y_{\mathrm{CH}_{4}, \mathrm{w}}} \frac{y_{\mathrm{O}_{2}, \mathrm{w}}}{k_{\mathrm{O}_{2}}+y_{\mathrm{O}_{2}, \mathrm{w}}}$

where $Q_{\mathrm{CH}_{4}}^{*}$ (unit: $\mathrm{mol} \mathrm{m}^{-3} \mathrm{~s}^{-1}$ ) is the oxidation potential when aqueous $\mathrm{O}_{2}$ and $\mathrm{CH}_{4}$ are not limited, and $k_{\mathrm{CH}_{4}}$ and $k_{\mathrm{O}_{2}}$ are Michaelis-Menten constants (unit: $\mathrm{mol} \mathrm{m}^{-3}$ water) for $\mathrm{CH}_{4}$ and $\mathrm{O}_{2}$. We use values of $0.44 \mathrm{~mol} \mathrm{~m}^{-3}$ water and $0.33 \mathrm{~mol} \mathrm{~m}^{-3}$ water, respectively, for $k_{\mathrm{CH}_{4}}$ and $k_{\mathrm{O}_{2}}$ (Arah and Kirk, 2000). $Q_{\mathrm{CH}_{4}}^{*}$ is defined in Appendix B.

The consumption of $\mathrm{O}_{2}$ due to heterotrophic respiration and $\mathrm{CH}_{4}$ oxidation is modeled as

$Q_{\mathrm{O}_{2}}=2 Q_{\mathrm{CH}_{4}}+V_{\mathrm{R}}^{*} \frac{y_{\mathrm{O}_{2}, \mathrm{w}}}{k_{\mathrm{R}}+y_{\mathrm{O}_{2}, \mathrm{w}}}$

where $V_{R}^{*}$ is the maximum rate of respiration when $\mathrm{O}_{2}$ is not the limiting factor, $k_{\mathrm{R}}$ is the Michaelis-Menten constant, using a value of $0.22 \mathrm{~mol} \mathrm{~m}^{-3}$ water (Arah and Kirk, 2000). As in Matthews et al. (2000), we assumed only the process of heterotrophic respiration competes with the process of methanotrophy for $\mathrm{O}_{2}$, thus $V_{\mathrm{R}}^{*}$ is twice that of $P_{\mathrm{CH}_{4}}^{*}$. We also neglected the $\mathrm{O}_{2}$ consumption by electron acceptor reoxidation (Segers and Leffelaar, 2001; van Bodegom et al., 2001) for the moment. Since no $\mathrm{O}_{2}$ is produced in the soil, $P_{\mathrm{O}_{2}}$ is set to zero. 


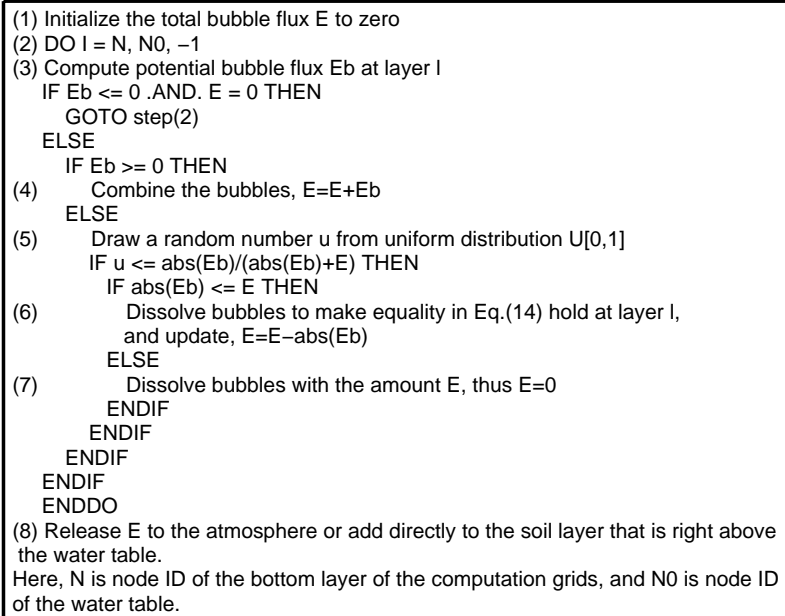

Fig. 2. The probabilistic algorithm used in the S4 model to compute ebullition.

Carbon dioxide is produced in methanogenesis, methanotrophy and aerobic respiration:

$P_{\mathrm{CO}_{2}}=P_{\mathrm{CH}_{4}}+Q_{\mathrm{O}_{2}}-Q_{\mathrm{CH}_{4}}$

Just as for $\mathrm{O}_{2}$ consumption, $\mathrm{CO}_{2}$ production from electron acceptor reduction (Conrad, 1989) was also neglected here. In the soil, consumption of $\mathrm{CO}_{2}$ is zero, therefore, $Q_{\mathrm{CO}_{2}}=0$.

For $\mathrm{N}_{2}$, we assumed no production and consumption in the soil profile, therefore, $P_{\mathrm{N}_{2}}=Q_{\mathrm{N}_{2}}=0$.

\subsubsection{The pressure-based ebullition algorithm}

We revised TEM to consider effects of hydrostacy on ebullition. Tokida et al. (2007) observed an abrupt change in the $\mathrm{CH}_{4}$ emission rates associated with a decreasing atmospheric pressure, and the mixing ratio of $\mathrm{CH}_{4}$ in the gas bubbles was no more than 50\% (see their Fig. 2). Zona et al. (2009) found that, when the surface standing water increased, the $\mathrm{CH}_{4}$ efflux was effectively retarded. Such behavior has not been explicitly considered and modeled in the process-based $\mathrm{CH}_{4}$ models with the conventional algorithms of ebullition using a prescribed threshold of water dissolved $\mathrm{CH}_{4}$ (e.g., Walter and Heimann, 2000; Arah and Kirk, 2000; Zhuang et al., 2004). Tokida et al. (2007) suggested a three-substance system, including $\mathrm{CH}_{4}, \mathrm{CO}_{2}$ and $\mathrm{N}_{2}$, should be used to model the ebullition. Indeed, Bazhin $(2001,2004)$ suggested that ebullition is triggered at a certain depth when the total pressure of the water-dissolved gases exceeds the hydrostatic pressure imposed at that depth by the water table and atmospheric pressure. Therefore, the simple concentrationbased threshold approach was replaced by an equation of hydrostatic equilibrium. In this study, we considered a foursubstance system, i.e. $\mathrm{CH}_{4}, \mathrm{O}_{2}, \mathrm{CO}_{2}$ and $\mathrm{N}_{2}$, and ignored other possible trace gases (e.g. argon and hydrogen). We formulated the bubbling criterion (Fig. 1) as

$P_{s}=\sum_{i} P_{s i}=\sum_{i} \frac{y_{i, \mathrm{w}}(z)}{H_{i}(z)} \geq P_{0}\left(\hat{p}+\frac{b}{z_{0}}+\frac{z_{\mathrm{d}}}{z_{0}}\right)=$ head

where $P_{s i}$ is the partial pressure and $H_{i}$ (see Appendix A for the formula) is the Henry's law constant for gas $i, \hat{p}\left(=p / P_{0}\right)$ is the scaled atmospheric pressure, $P_{0}=10^{5} \mathrm{~Pa}, z_{0}=10 \mathrm{~m}$, and $z_{\mathrm{d}}=\min \left(z-z_{\mathrm{s}}, z-z_{\mathrm{wt}}\right)$, and

$b= \begin{cases}z_{\mathrm{s}}-z_{\mathrm{wt}}, & \text { if } z_{\mathrm{wt}}<0 \\ \int_{z_{\mathrm{s}}}^{z_{\mathrm{st}}} \frac{\theta(z)}{\theta_{\mathrm{s}}(z)} d z, & \text { if } z_{\mathrm{wt}} \geq 0\end{cases}$

where $z_{\mathrm{s}}$ is the depth of soil surface, set to 0.0 ; and head (unit: Pa) is the total hydrostatic pressure head imposed by atmosphere and water above depth $z$. The second equation in Eq. (15) accounts for the capillary force by considering the rate of saturation of the soil. Further we assumed bubbling only occurs below the water table, thus $z_{\mathrm{d}}$ is always nonnegative. Note, in Eq. (14), we did not consider the effects of bubble shapes and number of bubbles, which would impact the surface tension between the bubble and water interface and consequently the bubbling criterion (Peck, 1960). We also neglected the change of water distribution caused by the ebullition (Rosenberry et al., 2003), which would cause some bubbles to be trapped and released later.

With Eq. (14), the potential ebullition for gas $i$ at a certain depth $z$ is computed as

$E_{b i}=\int_{z_{\mathrm{wt}}}^{Z_{\mathrm{soil}}}\left(y_{i}(s)-\tilde{y}_{i}(s)\right) \delta(s-z) d s$

where the equilibrium bulk concentration is

$\tilde{y}_{i}=\left(\epsilon / \alpha_{i}+\theta\right) \tilde{y}_{i, \mathrm{w}}$

and the equilibrium aqueous concentration is

$\tilde{y}_{i, \mathrm{w}}=\operatorname{head} \frac{P_{s i}}{P_{\mathrm{s}}} H_{i}(z)$

and $\delta(s)$ is the Dirac delta function. The potential ebullition computed from Eq. (16) can either be positive or negative, with positive implying bubble formation, and negative implying potential bubble re-dissolution.

To partly account for the fact that a fraction of the bubbles could be re-dissolved during their travel to the atmosphere (e.g., Martens and Klump, 1980), we used the algorithm in Fig. 2 to compute the ebullition. In this probabilistic algorithm, the possibility $\left(p_{\mathrm{r}}\right)$ of re-dissolution is proportional to the potential fraction of re-dissolution $\operatorname{abs}\left(E_{b}(z)\right) /\left[\operatorname{abs}\left(E_{b}(z)\right)+E(z)\right]$ (if $E_{b}(z)$ is negative calculated from Eq. 16). We modeled the re-dissolution as a yes/no process, if the random number $u$ drawn from a uniform distribution $U[0,1]$ is less than $p_{\mathrm{r}}$, dissolve the bubbles with an amount of $\operatorname{abs}\left(E_{b}(z)\right)$ (or $E(z)$ if $E(z) \leq \operatorname{abs}\left(E_{b}(z)\right)$ ), 
otherwise, bubbles continue moving upward without redissolution, and combine with possible bubbles generated at upper layers.

The algorithm was applied starting from the bottom of soil column to the level of water table. The total ebullition $E$ is either released directly to the atmosphere or added to the soil column, depending on the location of water table. When the water table is at or above the soil surface, the gases carried in the bubbles are directly emitted to the atmosphere; otherwise, they are added to the soil layer right above the water table.

There is an alternative way to implement the above ebullition algorithm, i.e. using the volumetric criteria, such as in Kellner et al. (2006); Granberg et al. (2001), and most recently in Wania et al. (2010). Using the ideal gas law, the volume of substances in gaseous phase in equilibrium with the aqueous phase can be computed at all depths. The gas volumes are then compared with some predefined threshold to trigger the bubbles. However, such a threshold is fuzzy and varies temporally and spatially due to a group of different factors (Baird et al., 2004; Kellner et al., 2006). Our implementation relates the ebullition directly to the pressure. As such, the ebullition criteria can be determined physically using the available information on gas content and soil water elevations. Also, our algorithm does not need to make any assumption of the relative fractions of different gases in the bubbles (Kellner et al., 2006). Arguably, ebullition can even occur without the existence of $\mathrm{CH}_{4}$, as long as the buoyancy is greater than the weight of the bubble. There are processes that have not been accounted for in the algorithm, e.g. entrapped gas due to a wetting process from the soil surface down into the column, which could cause bubble formation (Kellner et al., 2006). Solutions should be found in future studies to address such events. It is likely that our algorithm will not always give superior results to that obtained using the volume-threshold-based method in other studies (e.g., Wania et al., 2010, and comparison is needed). However, ease of implementation will favor inclusion of this approach for other gases in future modeling.

\subsubsection{Other transport routes and model implementations}

We revised the pathways of diffusion and plant-aided transport in Zhuang et al. (2004) (see Appendix C for details). These and other processes described in previous sections gave the governing equations for $\mathrm{CH}_{4}, \mathrm{CO}_{2}, \mathrm{O}_{2}$ and $\mathrm{N}_{2}$ involved in the four-substance model in Appendix $\mathrm{C}$.

As a result, the net $\mathrm{CH}_{4}$ efflux was computed

$$
\begin{aligned}
F_{\mathrm{CH}_{4}}= & -\left(D_{\mathrm{CH}_{4}} \frac{\partial y_{\mathrm{CH}_{4}}}{\partial z}\right)_{z=0}+\left(1-P_{\mathrm{OX}}\right) \int_{Z_{\mathrm{soil}}}^{z_{\mathrm{s}}} R_{\mathrm{CH}_{4}} d z \\
& + \text { Heaviside }\left(z_{\mathrm{s}}-z_{\mathrm{wt}}\right) E_{\mathrm{CH}_{4}}\left(z_{\mathrm{wt}}\right)
\end{aligned}
$$

where $P_{\mathrm{OX}}$ is set to 0.5 for the one-substance model (Walter and Heimann, 2000) and 0.0, otherwise.
We used the mass balance approach to calculate the diffusive flux to avoid the ambiguity in choosing the depth for computation (Rothfuss and Conrad, 1998). The governing equation Eq. (1) was solved using the method of lines (Schiesser, 1991) with a first order implicit projectorcorrector method for the reaction terms. The integration was done with a time step of $2400 \mathrm{~s}$. The soil column was approximated to a depth of $4 \mathrm{~m}$ with an exponentially stretching grid (a total of 40 nodes) that has finer grid resolution at the top and coarser grid resolution at the bottom (Oleson et al., 2004).

The revised $\mathrm{TEM} \mathrm{CH}_{4}$ module has three different levels of complexity: the one-substance model (S1 model hereafter) was obtained by (1) retaining the processes of methanogenesis and methanotrophy, (2) excluding processes involving other traces gases and (3) modeling ebullition with the conventional algorithm using a prescribed threshold $\mathrm{CH}_{4, \max }$ equal to $1.31 \mathrm{~mol} \mathrm{~m}^{-3}$ water (at $25^{\circ} \mathrm{C}$ ); similarly, the twosubstance model ( $\mathrm{S} 2$ model hence after) was obtained by considering $\mathrm{CH}_{4}$ and $\mathrm{O}_{2}$ simultaneously and modeling the ebullition with the concentration-based threshold approach, where $\mathrm{O}_{2, \max }$ equal to $1.23 \mathrm{~mol} \mathrm{~m}^{-3}$ water (at $25^{\circ} \mathrm{C}$ ) and $\mathrm{CH}_{4, \text { max }}$ equal to $1.31 \mathrm{~mol} \mathrm{~m}^{-3}$ water $\left(\right.$ at $25^{\circ} \mathrm{C}$ ); when four gases were considered and ebullition was modeled with the new probabilistic pressure-based algorithm, a four-substance model (S4 model hereafter) was obtained.

\subsection{Study sites}

Two temperate peatlands located in southern Michigan on the Edwin S. George Reserve, a University of Michigan field station were used to test our revised $\mathrm{CH}_{4}$ module. Three years of measurements from 1991 to 1993 were taken at Buck Hollow Bog and Big Cassandra Bog $\left(42^{\circ} 27^{\prime} \mathrm{N}, 84^{\circ} 1^{\prime} \mathrm{W}\right)$. Buck Hollow Bog is an open peatland covered by a wet lawn of Sphagnum species, with a dense cover of Scheuchzeria palustris, an arrow-grass. Three flux chambers were grouped in a triangular pattern approximately $10 \mathrm{~m}$ apart to measure the net $\mathrm{CH}_{4}$ flux in the Buck Hollow Bog. Measurements were taken at four sites at the Big Cassandra Bog. Sites 2 and 3 were used in this study, because these two sites are similar in terms of ecosystem conditions. The sites at the Big Cassandra Bog are dominated by Sphagnum and Polytrichum mosses and are covered by a dense stand of Chamaedaphne calyculata. Measurements of net $\mathrm{CH}_{4}$ fluxes were made using static chambers, and gas samples were collected and analyzed within 3-4 days of collection on a Shimadzu GC-14A gas chromatograph with a flame ionization detector. Environmental variables including water table depth and soil temperature from $5 \mathrm{~cm}$ above the peat surface to $100 \mathrm{~cm}$ within the peat column were monitored and used as driving data for the model in this study. Available pore water concentration profiles (with a detection limit $0.1 \mu \mathrm{M}$ ) were also used in our assessment of the model. For a detailed description of the study sites and assessment of measurements, readers can refer to Shannon and White (1994). 


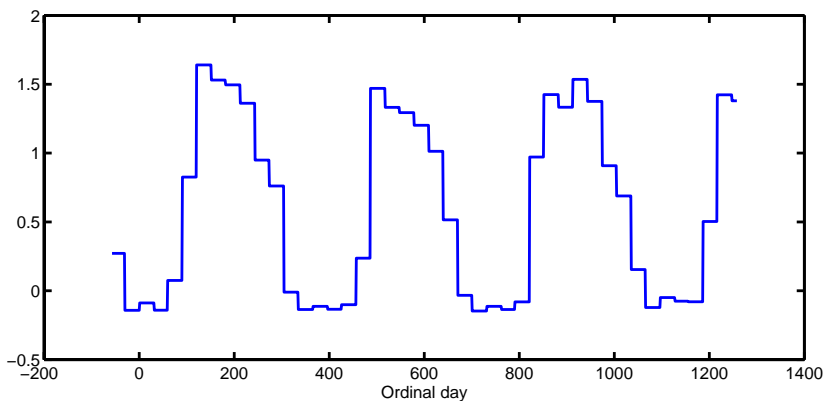

Fig. 3. The time series of scaled NPP (scaled with the median peak NPP at the site from a 100-year simulations) used as driving data in this study. Same data were used at both sites, with truncation into proper time periods.

\subsection{Standard simulations}

Standard simulations were conducted to evaluate the performances of the different models at both sites. The different model formulations were considered to include individual parameters whose values were calibrated in a modelspecific way by trial and error. Specifically, we modified the parameter values to match the simulated fluxes and pore water concentrations as closely as possible to the measurements (Table 1), so that the differences between different model simulations were mainly due to different model formulations. We used the measured water table depth and soil temperature as environmental forcing. Since no site-specific measurements of atmospheric pressure were available, we simply set total pressure to $1 \mathrm{~atm}$, a standard value that has been used in other model studies (Walter and Heimann, 2000; Zhuang et al., 2004). For soil porosity, we assumed a value of $0.83 \mathrm{v} \mathrm{v}^{-1}$ for depths shallower than $0.5 \mathrm{~m}$, linearly decreasing to $0.53 \mathrm{v} \mathrm{v}^{-1}$ at $0.9 \mathrm{~m}$, and constant at $0.53 \mathrm{v} \mathrm{v}^{-1}$ to the lower boundary of $4 \mathrm{~m}$. The scaled NPP data (Fig. 3) required to model $\mathrm{CH}_{4}$ production were derived from simulations using TEM driven with monthly climate data (Mitchell et al., 2004). For the atmospheric mixing ratio of the gases involved, we assume $0.209 \mathrm{v} \mathrm{v}^{-1}$ for $\mathrm{O}_{2}, 0.781 \mathrm{v} \mathrm{v}^{-1}$ for $\mathrm{N}_{2}$, 385 ppmv for $\mathrm{CO}_{2}$ and $1740 \mathrm{ppbv}$ for $\mathrm{CH}_{4}$ (Forster et al., 2007).

\subsection{Model sensitivity studies}

To test the responses of the different models to water table dynamics, we ran our models with the time series of water table depth artificially increased or decreased over a specific time period during the emission season. As shown in Fig. 4, for the Buck Hollow site, we increased the water table by $10 \mathrm{~cm}$ between ordinal day 150 and 160 (1 January 1991 was set to ordinal day 1 ), and decreased by $10 \mathrm{~cm}$ between ordinal day 590 and 600; for the Big Cassandra site, we increased the water table depth by $10 \mathrm{~cm}$ between ordinal day 135 and 145 , and decreased by $10 \mathrm{~cm}$ between ordinal day 689 and

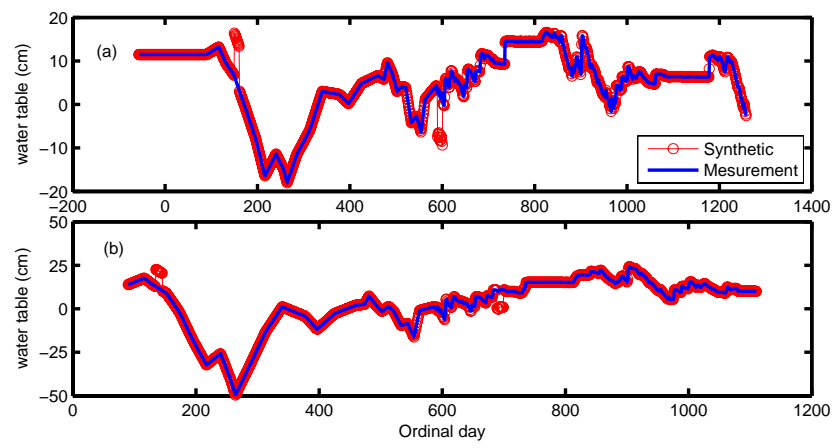

Fig. 4. The time series of water table depth used as driving data in this study at: (a) Buck Hollow site; (b) Big Cassandra site.

699. These days were chosen such that the differences of the $\mathrm{CH}_{4}$ effluxes between the standard simulations and sensitivity simulations were significant enough to be identified. The results were analyzed by comparing simulations with those from standard simulations.

Two sets of experiments were used to test the model response to atmospheric pressure change. First, we conducted sensitivity simulations using a time series of artificially perturbed low pressure or high pressure events (specifically $930 \mathrm{hPa}$ low and $1045 \mathrm{hPa}$ high) on two arbitrarily chosen days during the high-emission season in summer (Fig. 5). These two days were chosen based on the same criteria as that used in the water table sensitivity study. The effect of changing atmospheric pressure was analyzed by comparing the change in pathways of $\mathrm{CH}_{4}$ transport with that from the standard simulation. This was used to analyze whether the response is physically consistent or not. A second test was carried out to evaluate the overall effect of atmospheric pressure variability using a time series of atmospheric pressure (Fig. 6) extracted from the European Centre for Medium-Range Weather Forecasts (ECMWF) Interim reanalysis dataset at the grid that encompassed the site for the same time period of measurement. The response was again analyzed by comparing the results to the standard simulations.

\section{Results and discussion}

\subsection{Comparisons between standard model simulations and site-level observations}

All models resulted in similar $\mathrm{CH}_{4}$ fluxes (Table 2). Specifically, for the Buck Hollow site, the S1, S2 and S4 models all captured the temporal variability of the $\mathrm{CH}_{4}$ fluxes (Fig. 7a). Because of the probabilistic feature of the S4 model, mulitple runs were conducted. The differences from these multiple runs were indistinguishable because the emission routes at these two sites were dominated by plantaided transport, and bubble redissolution rarely occured. The 
Table 1. Parameters calibrated for standard model simulations.

\begin{tabular}{lrlll}
\hline & $\begin{array}{r}\hat{P}_{\mathrm{CH}_{4}} \\
\left(\mathrm{~mol} \mathrm{~m}^{-3} \mathrm{~s}^{-1}\right)\end{array}$ & $\begin{array}{l}P_{Q_{10}} \\
(\text { None })\end{array}$ & $\begin{array}{l}\hat{O}_{\mathrm{CH}_{4}} \\
\left(\mathrm{~mol} \mathrm{~m}^{-3} \mathrm{~s}^{-1}\right)\end{array}$ & $\begin{array}{l}R_{\mathrm{veg}} \\
(\text { None })\end{array}$ \\
\hline Buck Hollow site & & & & \\
\hline S1-model & $3.5 \times 10^{-7}$ & 12.7 & $1.10 \times 10^{-7}$ & $1.2 \times 10^{-3}$ \\
S2-model & $2.5 \times 10^{-6}$ & 12.7 & $1.10 \times 10^{-8}$ & $1.2 \times 10^{-3}$ \\
S4-model & $1.25 \times 10^{-6}$ & 12.7 & $1.10 \times 10^{-8}$ & $1.2 \times 10^{-3}$ \\
\hline Big Cassandra site & & & & \\
\hline S1-model & $7.5 \times 10^{-8}$ & 6 & $1 \times 10^{-7}$ & $1 \times 10^{-3}$ \\
S2-model & $2.75 \times 10^{-6}$ & 6 & $5 \times 10^{-8}$ & $1 \times 10^{-3}$ \\
S4-model & $1.375 \times 10^{-6}$ & 6 & $1 \times 10^{-7}$ & $1 \times 10^{-3}$ \\
\hline
\end{tabular}

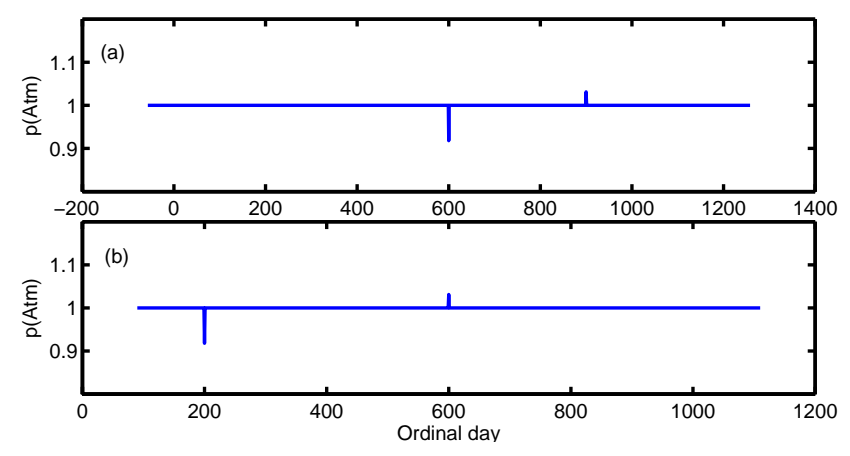

Fig. 5. Synthetic atmospheric pressure used in simulations for sensitivity analysis at: (a) Buck Hollow site; (b) Big Cassandra site.

mean from an ensemble simulation of size four was shown for comparison. The S4 model performed best in terms of linear fitting and the root mean square error (RMSE) against the measurements (Table 2). The S1 model presented the second best results, with the simplest model structure. Over the three-year period, the simulated mean daily fluxes were $107.00 \mathrm{mg} \mathrm{CH}_{4} \mathrm{~m}^{-2} \mathrm{~d}^{-1}, 168.82 \mathrm{mg} \mathrm{CH}_{4} \mathrm{~m}^{-2} \mathrm{~d}^{-1}$ and $114.43 \mathrm{mg} \mathrm{CH}_{4} \mathrm{~m}^{-2} \mathrm{~d}^{-1}$, respectively by the $\mathrm{S} 1, \mathrm{~S} 2$ and $\mathrm{S} 4$ model. The $\mathrm{S} 2$ model gave almost $50 \%$ higher emission than did the S1 and S4 model. In the S1 simulation, the maximum production rate was at least an order of magnitude smaller than those of S2 and S4 models because it included no inhibition effect of $\mathrm{O}_{2}$ on methanogenesis (Table 1). The maximum oxidation rates $\left(\hat{O}_{\mathrm{CH}_{4}}\right)$ were similar in magnitude. Note that the simulations (except S4) were not very sensitive to $\hat{O}_{\mathrm{CH}_{4}}$.

The importance of different $\mathrm{CH}_{4}$ transport pathways varied in different models (Fig. 7a). Diffusion played a significant role in the release of $\mathrm{CH}_{4}$ into the atmosphere, even though plant transport remained the dominant pathway in S4 simulations. In S2 simulations, plant transport accounted for more than $90 \%$ of the efflux into the atmosphere. The

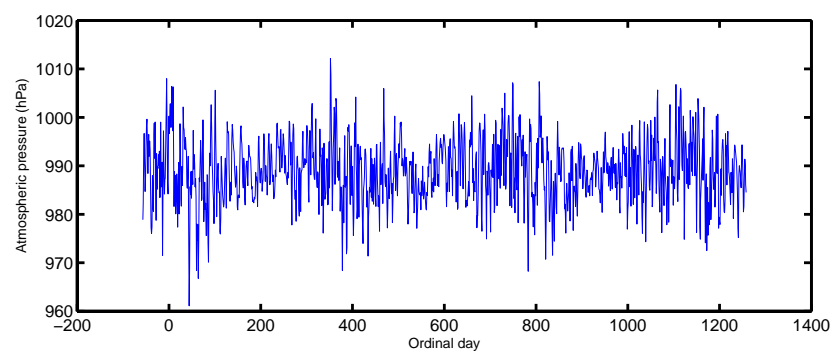

Fig. 6. Transient atmospheric pressure used in simulations for sensitivity analysis. The same time series was applied at both sites, with truncation into proper time periods.

modeled diffusion contribution to efflux reached a short-term maximum between day 170 and 180 in the S1 simulations. This was due to a sudden and substantial decrease in water table from above the peat surface to below the peat surface (Fig. 4). This increased the concentration gradient of the $\mathrm{CH}_{4}$ near the peat surface and thus increased diffusion. Such short-term changes were also found in the S2 and S4 simulations, but with smaller magnitudes. All the models suggested that the efflux through ebullition was small, which agrees with measurements (Shannon and White, 1994). In the $\mathrm{S} 4$ simulation, the ebullition played a larger role than it did in $\mathrm{S} 1$ and $\mathrm{S} 2$ simulations.

S1 performed the best in simulating pore water concentrations; followed by the S2 model and then the S4 model (Fig. 7a). For 12 June 1993, none of the models presented a satisfying result. The discrepancy might be due to the nonlinearities of the transient simulations. For example, the pore water concentrations at a certain day were impacted by results in previous days. Uncertainty in the driving data (e.g. soil temperature) is another source of such discrepancy.

At the Big Cassandra site, the simulated effluxes were less satisfying than the Buck Hollow Bog site, though S4 model performed the best, followed by the S2 model and then S1 

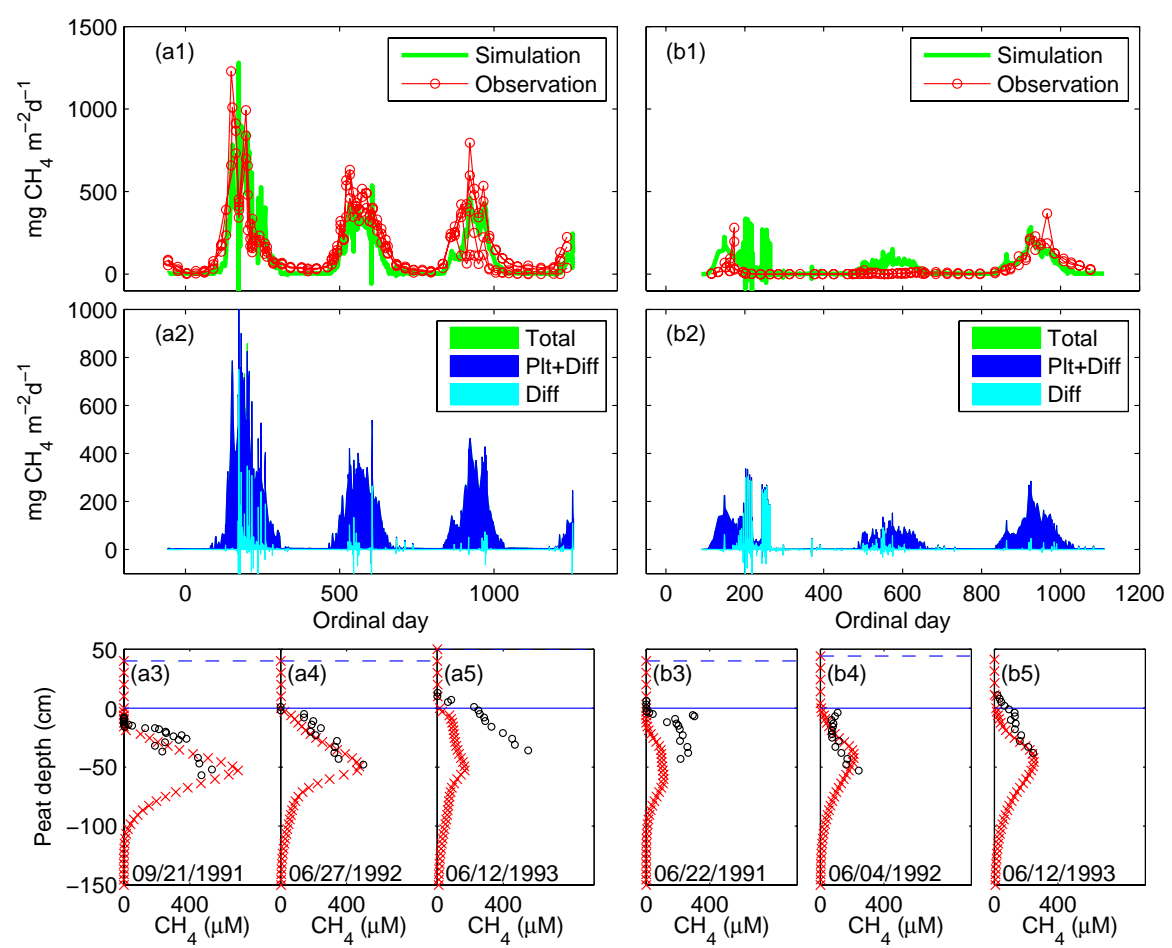

Fig. 7a. Methane effluxes, component-wise emissions and pore water concentration profiles from one-substance model (S1 model) in the standard simulations. (a) Panels for the Buck Hollow site. (b) Panels for the Big Cassandra site. Dashed lines indicate the level of water tables.
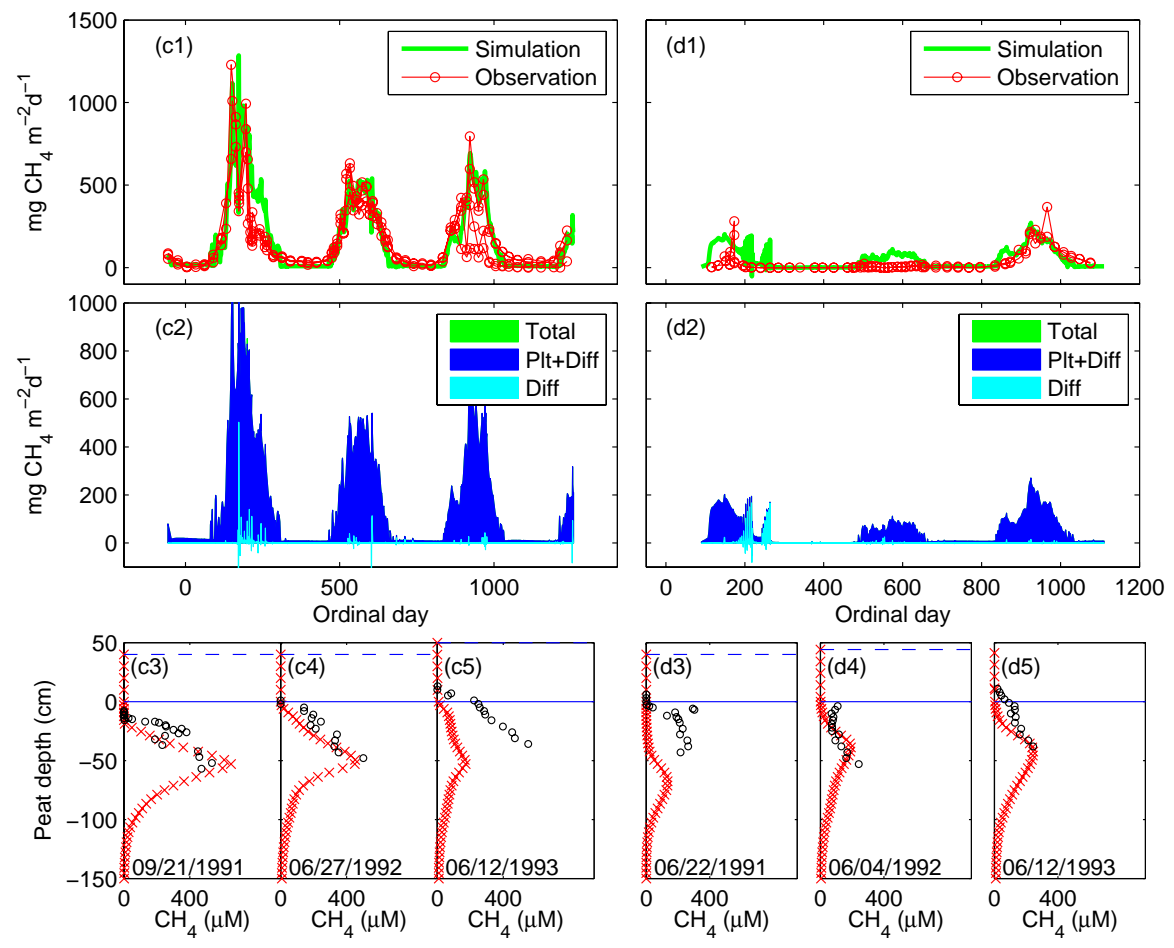

Fig. 7b. Methane effluxes, component-wise emissions and pore water concentration profiles from two-substance model (S2 model) in the standard simulations. (c) Panels for the Buck Hollow site. (d) Panels for the Big Cassandra site. Dashed lines indicate the level of water tables. 

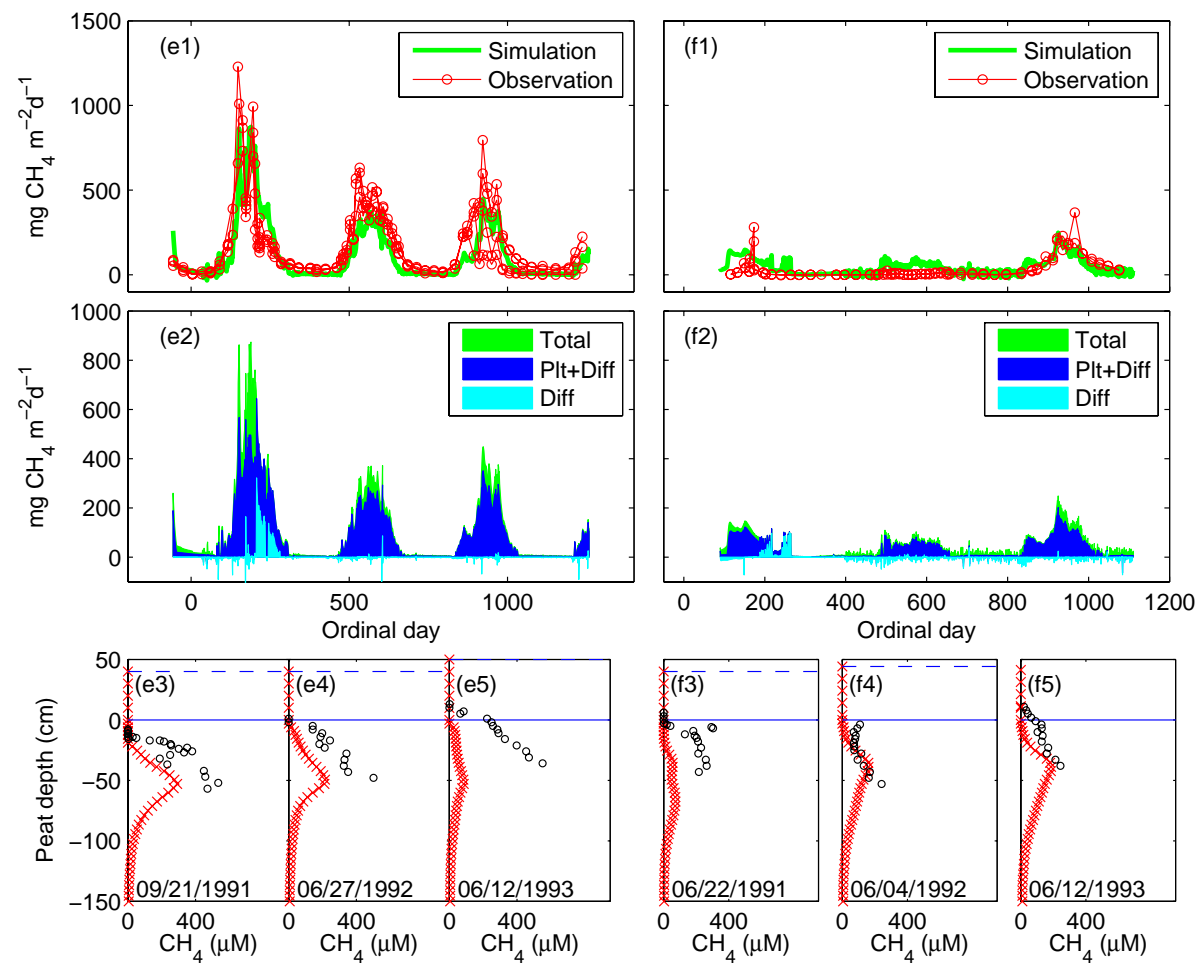

Fig. 7c. Methane effluxes, component-wise emissions and pore water concentration profiles from four-substance model (S4 model) in the standard simulations. (e) Panels for the Buck Hollow site. (f) Panels for the Big Cassandra site. Dashed lines indicate the level of water tables.

Table 2. Comparison of $\mathrm{CH}_{4}$ efflux from the standard simulations to the measurements at the two Michigan peatlands. All statistics were tested for significance and were found significant with $p<0.001$.

\begin{tabular}{lccll}
\hline & $\begin{array}{l}\text { Slope } \\
\text { (None) }\end{array}$ & $\begin{array}{l}\text { Intercept } \\
\left(\mathrm{mg} \mathrm{CH}_{4} \mathrm{~m}^{-2} \mathrm{~d}^{-1}\right)\end{array}$ & $\begin{array}{l}\mathrm{RMSE} \\
\left(\mathrm{mg} \mathrm{CH}_{4} \mathrm{~m}^{-2} \mathrm{~d}^{-1}\right)\end{array}$ & $\begin{array}{l}R^{2} \\
(\text { None })\end{array}$ \\
\hline Buck Hollow site & & & & 0.51 \\
\hline S1-model & 0.79 & 83.5 & 165.1 & 0.60 \\
S2-model & 0.65 & 50.1 & 168.6 & 0.55 \\
S4-model & 0.84 & 68.0 & 154.5 & 0.13 \\
\hline Big Cassandra site & & & & 0.27 \\
\hline S1-model & 0.31 & 15.9 & 86.6 & 0.31 \\
S2-model & 0.52 & -1.0 & 74.5 & 61.2 \\
S4-model & 0.78 & -10.8 & & \\
\hline
\end{tabular}

model. Particularly for the second half year of 1991 and the year 1992, the results compared poorly with measurements. This underperformance may be due to an inadequate representation of the methanogenesis substrate, which was simulated in TEM but has not been specifically calibrated for wetland ecosystems. For the three-year period, the mean daily fluxes were $42.51 \mathrm{mg} \mathrm{CH}_{4} \mathrm{~m}^{-2} \mathrm{~d}^{-1}, 50.83 \mathrm{mg} \mathrm{CH}_{4} \mathrm{~m}^{-2} \mathrm{~d}^{-1}$ and $45.51 \mathrm{mg} \mathrm{CH}_{4} \mathrm{~m}^{-2} \mathrm{~d}^{-1}$, respectively, by the $\mathrm{S} 1, \mathrm{~S} 2$ and
$\mathrm{S} 4$ models. Still, $\mathrm{S} 2$ simulated the highest $\mathrm{CH}_{4}$ emission among the three models. At this site, plant transport was the most important pathway, and ebullition was relatively unimportant. All three models presented similar results for pore water concentrations (Fig. 7a). 

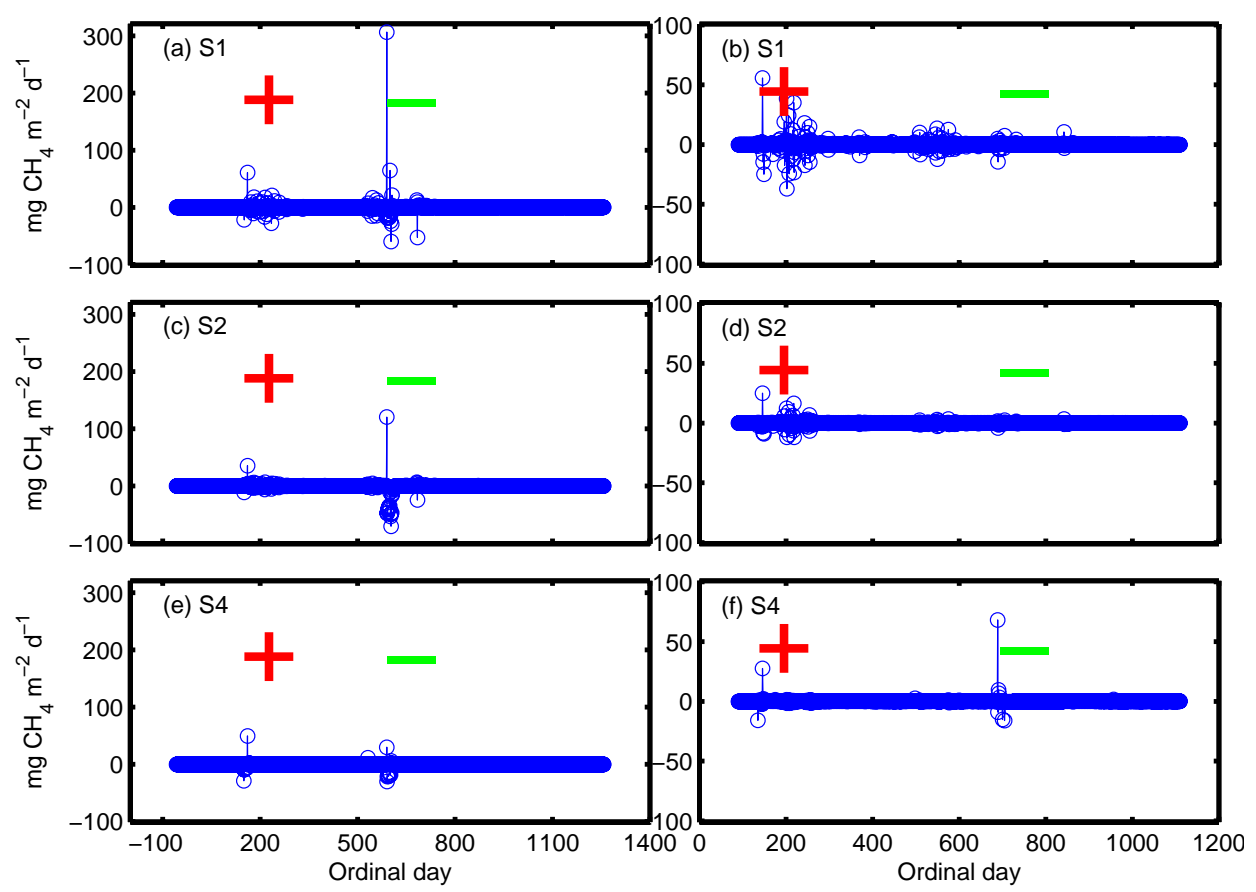

Fig. 8. Water table sensitivities with models of different complexities. Left-hand panels are for Buck Hollow site; right-hand panels are for Big Cassandra site. The red symbol "+" indicates the period of artificially increased water table depth, and the green symbol "-" indicates the period of artificially decreased water table depth.

\subsection{Model sensitivity analyses}

\subsubsection{Sensitivity to water table change}

We found that the response to a $10 \mathrm{~cm}$ change in surface standing water caused a change in the $\mathrm{CH}_{4}$ efflux by as much as $-50 \sim 300 \mathrm{mg} \mathrm{CH}_{4} \mathrm{~m}^{-2} \mathrm{~d}^{-1}$ (Fig. 8). Such responses depend on site characteristics and model complexity. At the Big Cassandra site, models S1 and S2 yielded a stronger response in effluxes to the water table increase than did the S4 model, while the opposite occurred for the water table decrease. At the Buck Hollow site, the responses of different models to the water table change were similar, but S1 gave a much stronger response to the water table decrease than did models S2 and S4. Nevertheless, all the models successfully predicted the retardation effect of an increase in surface standing water on $\mathrm{CH}_{4}$ efflux (Fig. 9). This can be explained by the low diffusivity of gases in water relative to air. A higher column of surface standing water represents a longer distance of diffusion before gas can escape into the atmosphere. This phenomenon may account for $\mathrm{CH}_{4}$ accumulation in the peat column, which in turn enhances plant mediated transport and the oxidation of $\mathrm{CH}_{4}$ in the rhizosphere, which decreases the efflux. When water table depth decreases, the diffusion distance is reduced, and efflux to the atmosphere increases (Fig. 9). In places where emergent vascular plants are sparse, a decrease in water table depth could enhance $\mathrm{CH}_{4}$ efflux through ebullition. This was tested by re- moving the plants and using the remaining parameters from Table 2 in the simulations. The results are shown in Fig. 10. We found that the S1 and S2 models had negligible ebullition compared to that from model S4 in response to changes in water table. The burst of ebullition predicted by model S4 was more significant at the onset of a drop in standing water level. Then it decreased as the water table continuously dropped and finally reached zero ebullition when the $\mathrm{CH}_{4}$ accumulation was too low to support ebullition. In contrast, the $\mathrm{S} 1$ and $\mathrm{S} 2$ models predicted that diffusion was the major pathway of $\mathrm{CH}_{4}$ efflux and greatly underestimated the $\mathrm{CH}_{4}$ emissions through ebullition. Field data from Buck Hollow site also supported ebullition as important when the vegetation is sparser (Shannon et al., 1996). These findings suggest that while models S1 and S2 performed relatively well with careful calibrations, the positive results were fortuitous. They represent an inadequate formulation but an artful parameterization of the problem.

\subsubsection{Sensitivity to atmospheric pressure change}

For the first sensitivity test of the models to atmospheric pressure change, S1 and S2 models showed much weaker $\left(10^{1} \sim 10^{2}\right.$ weaker) responses than that of the S4 model (Fig. 11). In both S1 and S2 models, a change in atmospheric pressure can only affect the atmospheric concentration of the gases. Given the small feasible range of atmospheric temperature change and atmospheric pressure change, the change in 

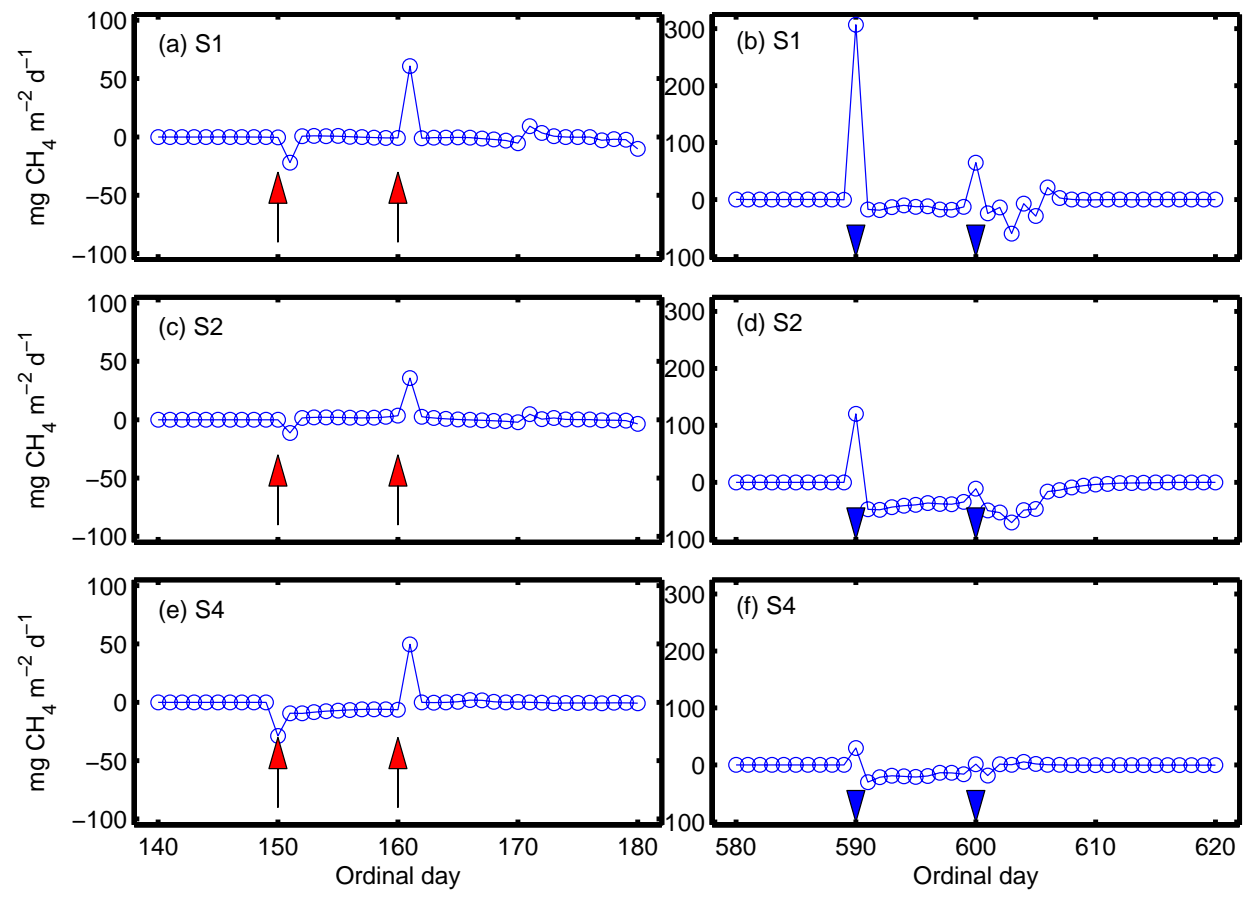

Fig. 9. Zoom-in plots for the water table sensitivity with models of different complexities at the Buck Hollow site. Left-hand panels were for the period where the water table depth is increased by $10 \mathrm{~cm}$ compared to the measured data, right-hand panels are for the period where the water table depth is decreased by $10 \mathrm{~cm}$. The arrows indicate when the specified water table change starts and ends.

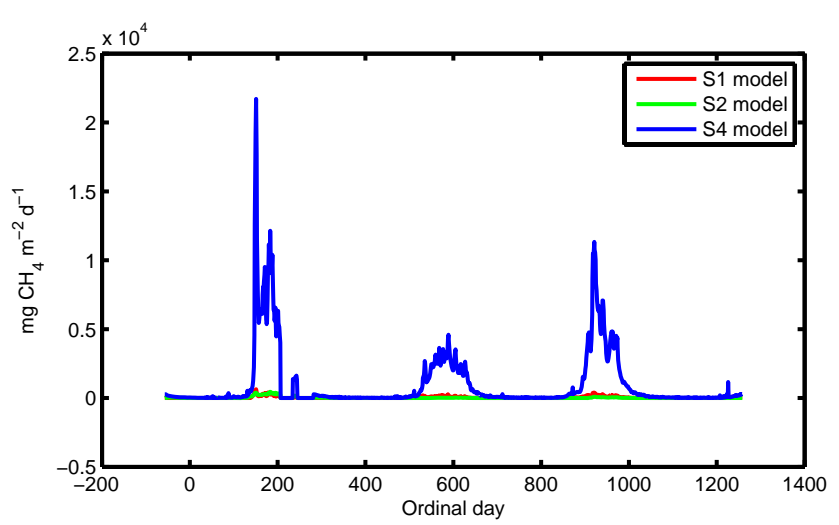

Fig. 10. Methane effluxes through ebullition at the Buck Hollow site when no vegetation is present to support plant aided transport. See text for details.

atmospheric $\mathrm{CH}_{4}$ concentration is small, implying a small change of the diffusion rate and thus the methane efflux in these two models. However, in the S4 model, the atmospheric pressure was further related to the ebullition fluxes. When a low atmospheric pressure occurred, the ebullition criterion became less restrictive, and bubbles were more easily formed, enhancing the ebullition. In this simulation, a decrease in atmospheric pressure could trigger an episodic increase in $\mathrm{CH}_{4}$ efflux by as much as $120 \mathrm{mg} \mathrm{CH}_{4} \mathrm{~m}^{-2} \mathrm{~d}^{-1}$ at the Buck Hollow site and as much as $80 \mathrm{mg} \mathrm{CH}_{4} \mathrm{~m}^{-2} \mathrm{~d}^{-1}$ at the Big Cassandra site, comparable to the enhancement due to a decrease in surface standing water table depth.

Results from the sensitivity tests of transient atmospheric pressure were analyzed, which we found were very different with the different models (see Fig. 12). For instance, in cases of low atmospheric pressure events at the Buck Hollow site, the S4 model usually predicted higher fluxes through enhancement of ebullition. For the S1 model, response to atmospheric pressure change was negligible. The S2 model also responded significantly to the change of atmospheric pressure, but showed lower fluxes in accordance with a lower concentration of atmospheric $\mathrm{CH}_{4}$ at the upper boundary. In cases of high pressure events, $\mathrm{S} 4$ yielded reduced the fluxes by suppressing ebullition, $\mathrm{S} 2$ yielded enhanced fluxes due to a higher atmospheric concentration of $\mathrm{CH}_{4}$ at the upper boundary, and S1 showed little response. Similar results were found at the Big Cassandra site. The change of atmospheric pressure also changed the rate of plant aided transport and diffusion. However, in our formulation of the algorithm, ebullition is the preferred route if it is triggered (which we also believe is true in the field, e.g. Tokida et al., 2005). By analyzing the cumulative differences, we found for the threeyear period at the Buck Hollow site that the S4 model predicted around 5\% more emitted $\mathrm{CH}_{4}$ using the transient atmospheric pressure data than it did using the standard $1 \mathrm{~atm}$ pressure. The $\mathrm{S} 2$ model, in contrast, predicted around 3\% 

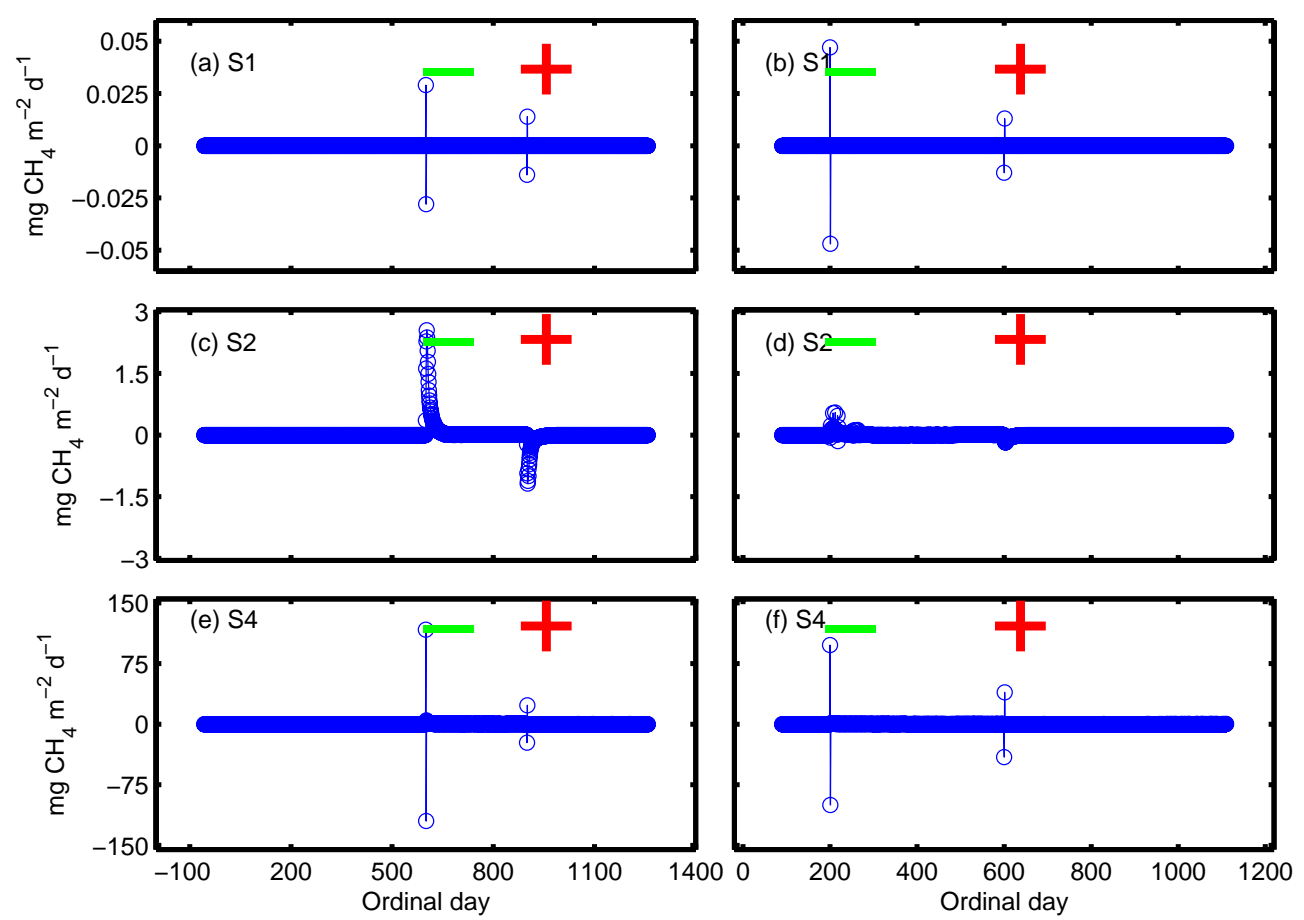

Fig. 11. Atmospheric pressure sensitivities with models of different complexities. (a), (c) and (e) panels are for Buck Hollow site; (b), (d) and (f) panels are for Big Cassandra site. The red symbol "+" indicates the day of artificially perturbed high pressure event, and the green symbol "-" indicates the day of artificially perturbed low pressure event. Note the scale of results from S4 model is $10^{2}$ of that from S2 model, and $10^{3}$ of that from S1 model.

less emission when the transient atmospheric pressure was used. Similar results were found for the Big Cassandra site, with smaller differences, in accordance with the lower emission rates.

\subsection{The importance of using temperature dependent parameters}

In our standard and sensitivity simulations with the revised $\mathrm{CH}_{4}$ module, we treated the phase-related parameters, such as diffusivities, Henry's law constants and Bunsen coefficients as temperature dependent. Analysis showed that, within the typical temperature range (e.g., -5 to $30^{\circ} \mathrm{C}$ ), the diffusivity of $\mathrm{CO}_{2}$ in water changed $\pm 5 \%$, the Henry's law constant and Bunsen coefficient changed $\pm 50 \%$ (results not shown). For $\mathrm{CH}_{4}$, its diffusivity in air changed $\pm 10 \%$ and in water changed $\pm 5 \%$, but the Henry's law constant and Bunsen coefficient changed $\pm 40 \%$. To test if fixing these parameters at a specific reference temperature could significantly affect the results, we conducted a set of simulations with the phase-related parameter values corresponding to a reference temperature of $12.5^{\circ} \mathrm{C}$.

We found, for the $\mathrm{S} 1$ model, that the temperature dependence of these parameters did not change the efflux significantly (Fig. 13). However, compared to the standard simulation, both the S2 and S4 models predicted a higher $\mathrm{CH}_{4}$ efflux during high emission periods. Given that soil temperatures at the two sites were often above the reference temperature during the high-emission summer season, the lower solubility computed with the reference temperature allowed less $\mathrm{O}_{2}$ and $\mathrm{CH}_{4}$ to be stored in the soil, given almost the same rate of $\mathrm{CH}_{4}$ production. Further, considering the inhibition effect of $\mathrm{O}_{2}$ on methanogenesis and the stimulus effect of $\mathrm{O}_{2}$ on methanotrophy, the higher emissions associated with the S2 and S4 models using coefficient values at the reference temperature is then explained as a stimulus of gas transport to the atmosphere. We conclude that fixing phase-related parameters at their reference temperature values is safe for the S1 model, but that temperature-dependent parameters should be used in the S2 and S4 models.

\subsection{The role of root density distribution}

Previous $\mathrm{CH}_{4}$ modeling has used a linear function for the vertical distribution of root density (e.g., Walter and Heimann, 2000; Zhuang et al., 2004; also see Eq. (D2) in Appendix D). However, root biomass is often found to be exponentially distributed (Jackson et al., 1996), and an exponential root distribution could also be used (e.g., van Huissteden et al., 2006). Here we implemented both linear and exponential root distribution functions in our revised $\mathrm{CH}_{4}$ module to test if they make a difference in $\mathrm{CH}_{4}$ effluxes (Tables 1-4) and 

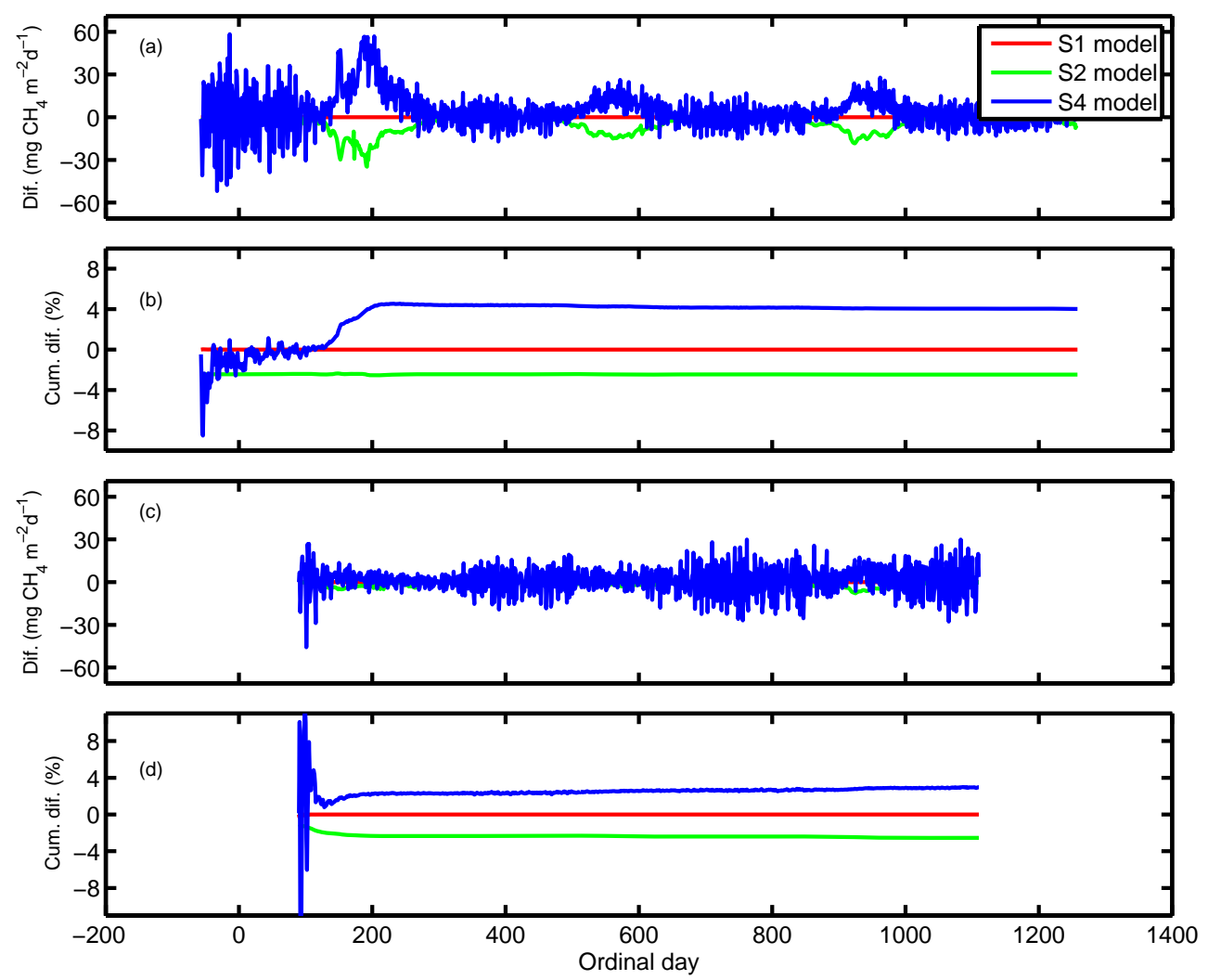

Fig. 12. Differences in the response to transient atmospheric pressure and that to constant atmospheric pressure with models of different complexities. (a) Time series of the absolute difference at the Buck Hollow site. (b) Time series of cumulative difference at the Buck Hollow site. (c) Time series of the absolute difference at the Big Cassandra site. (d) Time series of cumulative difference at the Big Cassandra site. The difference is defined by subtracting the fluxes simulated with the standard 1 atm pressure from that using the transient atmospheric pressure data.
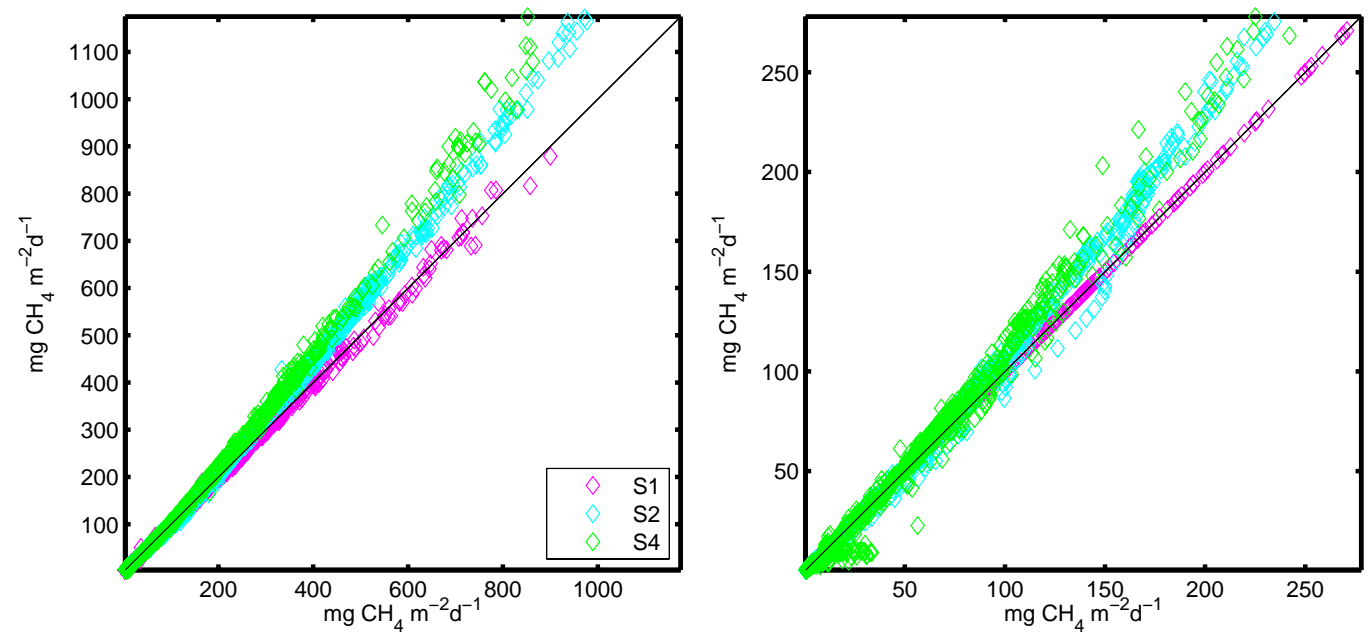

Fig. 13. Impact of temperature dependence of phase-related parameters on the $\mathrm{CH}_{4}$ efflux simulations with models of different complexities at: (a) Buck Hollow site; (b) Big Cassandra site. The black line denotes where $y=x$. The results from standard simulations were plotted as abscissa. 
Table 3. Parameters calibrated for model simulations using a linear root distribution function.

\begin{tabular}{lllll}
\hline & $\begin{array}{l}\hat{P}_{\mathrm{CH}_{4}} \\
\left(\mathrm{~mol} \mathrm{~m}^{-3} \mathrm{~s}^{-1}\right)\end{array}$ & $\begin{array}{l}P_{Q_{10}} \\
(\text { None })\end{array}$ & $\begin{array}{l}\hat{O}_{\mathrm{CH}_{4}} \\
\left(\mathrm{~mol} \mathrm{~m}^{-3} \mathrm{~s}^{-1}\right)\end{array}$ & $\begin{array}{l}R_{\mathrm{veg}} \\
(\text { None })\end{array}$ \\
\hline Buck Hollow site & & & & \\
\hline S1-model & $3.0 \times 10^{-8}$ & 12.7 & $1.10 \times 10^{-7}$ & $4.0 \times 10^{-2}$ \\
S2-model & $2.0 \times 10^{-6}$ & 12.7 & $1.10 \times 10^{-8}$ & $4.0 \times 10^{-2}$ \\
S4-model & $7.5 \times 10^{-7}$ & 12.7 & $1.10 \times 10^{-8}$ & $4.0 \times 10^{-2}$ \\
\hline Big Cassandra site & & & & \\
\hline S1-model & $5.0 \times 10^{-8}$ & 6 & $1 \times 10^{-7}$ & $1.5 \times 10^{-3}$ \\
S2-model & $1.5 \times 10^{-6}$ & 6 & $5 \times 10^{-8}$ & $1.5 \times 10^{-3}$ \\
S4-model & $5.0 \times 10^{-7}$ & 6 & $1 \times 10^{-7}$ & $1.5 \times 10^{-3}$ \\
\hline
\end{tabular}

Table 4. Comparison of $\mathrm{CH}_{4}$ efflux from the simulations using a linear root distribution function to the measurements at the two Michigan peatlands. All statistics were tested for significance and were found significant with $p<0.001$, except those denoted in the parentheses.

\begin{tabular}{lllll}
\hline & $\begin{array}{l}\text { Slope } \\
\text { (None) }\end{array}$ & $\begin{array}{l}\text { Intercept } \\
\left(\mathrm{mg} \mathrm{CH}_{4} \mathrm{~m}^{-2} \mathrm{~d}^{-1}\right)\end{array}$ & $\begin{array}{l}\mathrm{RMSE} \\
\left(\mathrm{mg} \mathrm{CH}_{4} \mathrm{~m}^{-2} \mathrm{~d}^{-1}\right)\end{array}$ & $\begin{array}{l}R^{2} \\
(\text { None })\end{array}$ \\
\hline Buck Hollow site & & & & 0.66 \\
\hline S1-model & 1.21 & 54.9 & 154.1 & 0.64 \\
S2-model & 0.78 & 47.9 & 139.8 & 0.22 \\
S4-model & 0.68 & 127.6 & 216.6 & $0.19(p=0.2)$ \\
\hline Big Cassandra site & & & & $0.07(p<0.01)$ \\
\hline S1-model & 0.10 & 32.1 & 103.7 & 0.14 \\
S2-model & 0.10 & 26.5 & 183.6 & \\
S4-model & 0.27 & 13.2 & 104.6 & \\
\hline
\end{tabular}

pore water concentrations. In both configurations, the parameter values were obtained from calibration based on measurement data. The differences between the simulations were thus mainly due to the different model configurations.

We found the contributions from different pathways were different when two different root density distribution functions were used (Figs. 7a and 14a). In the standard simulation using an exponential root density distribution function, ebullition played a minor role, whereas in the simulation employing a linear root density distribution, the ebullition was more significant, particularly in the S2 and S4 models. The ebullition was enhanced more at the Big Cassandra site than at the Buck Hollow site, suggesting that the responses of the models to two different root distribution functions are site dependent and related to the net $\mathrm{CH}_{4}$ production characteristics of the site. In the simulation employing the linear root distribution function, model-derived pore water $\mathrm{CH}_{4}$ concentration profiles underestimated field observations in the upper level of the peat column (Fig. 14a). The lower $\mathrm{CH}_{4}$ concentrations ware due to a poor representation of transport in the upper portion of the soil column when a linear root density function was used. Conversely, the exponential root distribution extends smoothly down into depth of the peat column, producing more realistic pore water $\mathrm{CH}_{4}$ concentration profiles. Therefore, though rigorous parameterization can lead to a good fit of the modeled $\mathrm{CH}_{4}$ fluxes with respect to the measurements, the model fails to capture other aspects of the measurements when an improper formulation of the problem is used. Also, in our case, the exponential distribution is a superior representation of root density as a function of depth.

\subsection{Issues for regional application of the different $\mathrm{CH}_{4}$ models}

The $\mathrm{CH}_{4}$ models of different complexities developed in this study can be used for regional hindcast and projection of wetland $\mathrm{CH}_{4}$ emissions provided that necessary climate forcing data are available. This is not a problem when these $\mathrm{CH}_{4}$ models are used inside a biogeochemistry model, such as TEM, where the necessary climate forcing data to the 

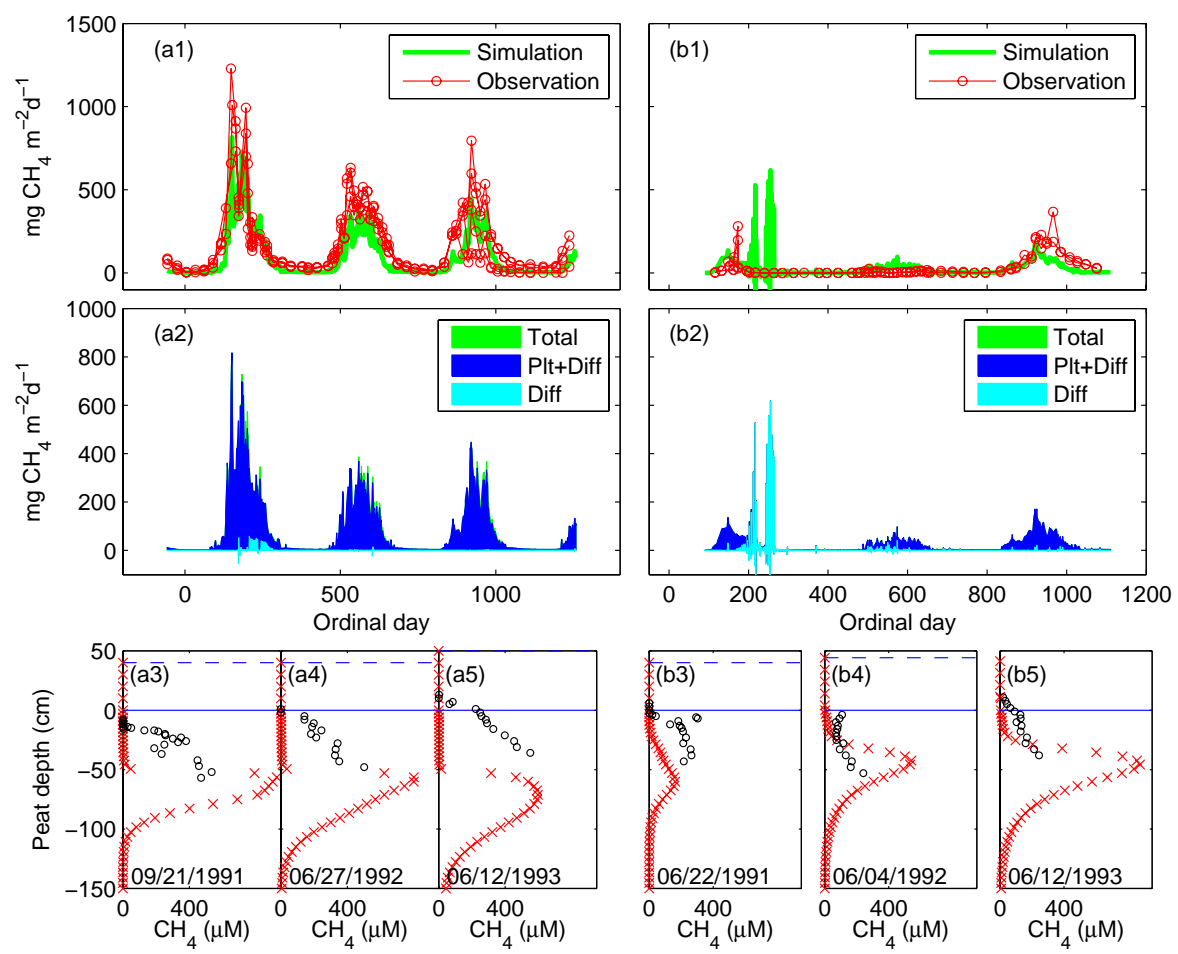

Fig. 14a. Methane effluxes, component-wise emissions and pore water concentration profiles from one-substance model (S1 model) in test simulations using a linear root distribution function. (a) Panels for the Buck Hollow site. (b) Panels for the Big Cassandra site. Dashed lines indicate the level of water tables.
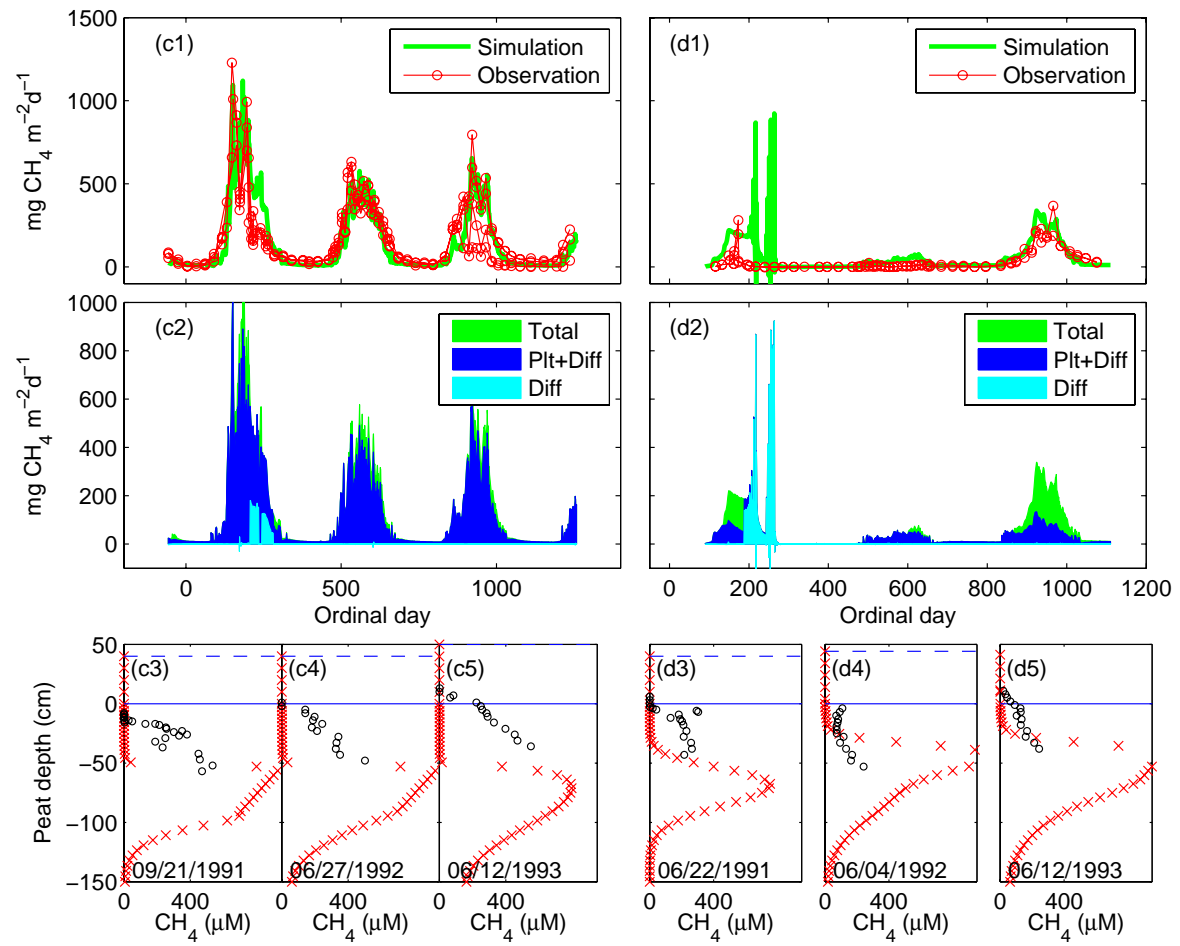

Fig. 14b. Methane effluxes, component-wise emissions and pore water concentration profiles from two-substance model (S2 model) in test simulations using a linear root distribution function. (c) Panels for the Buck Hollow site. (d) Panels for the Big Cassandra site. Dashed lines indicate the level of water tables. 

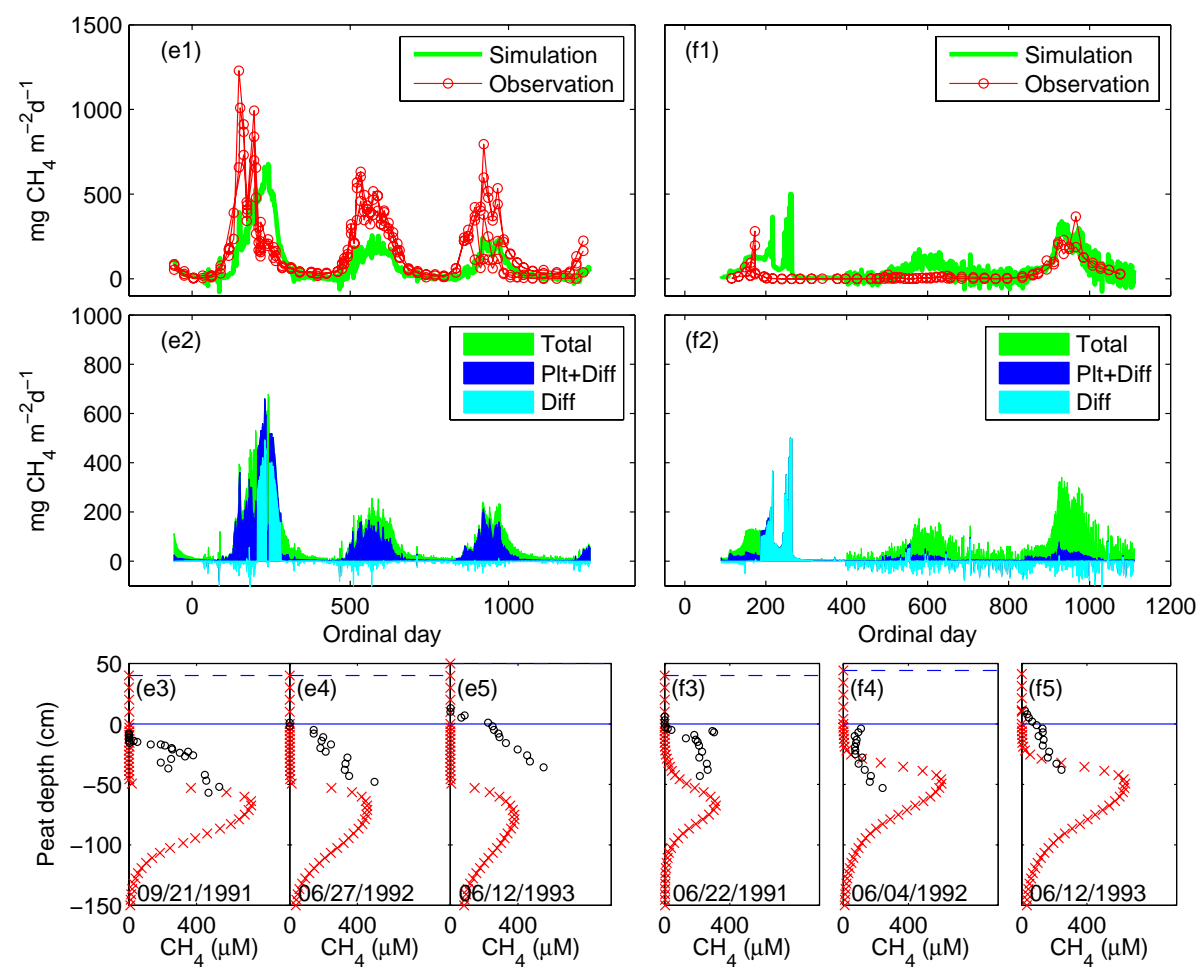

Fig. 14c. Methane effluxes, component-wise emissions and pore water concentration profiles from four-substance model (S4 model) in test simulations using a linear root distribution function. (e) Panels for the Buck Hollow site. (f) Panels for the Big Cassandra site. Dashed lines indicate the level of water tables.

$\mathrm{CH}_{4}$ models can be computed explicitly when the biogeochemistry model is driven by a climate dataset including air temperature, cloud fraction, precipitation and vapor pressure (Zhuang et al., 2004). The three $\mathrm{CH}_{4}$ models have almost the same requirement for climate forcing, except that the S4 model requires surface pressure data for a better performance. For historical simulations, the surface pressure data can easily be obtained from various climate data sources, e.g. datasets from NCEP Reanalysis and ECMWF Interim Reanalysis. For projections, GCM model outputs would be a source for the necessary climate data. In some cases, when sea level pressure data rather than surface pressure data are output from GCMs (e.g. models involved in IPCC AR4, http://www.ipcc-data.org/ar4/gcm_data.html). The surface pressure data can then be derived from a combination of sea level pressure data, information of air temperature, elevation and vapor pressure (Wallace, 2006). Although the $\mathrm{CH}_{4}$ models developed here have different complexities, they have almost the same number of parameters that require calibration. The more complicated S2 and S4 models have even fewer parameters to calibrate. For instance, the S2 and S4 models compute the fraction of $\mathrm{CH}_{4}$ oxidation in the rhizosphere explicitly - no parameterization is needed as in the $\mathrm{S} 1$ model.
The parameters of the $\mathrm{CH}_{4}$ models should be handled carefully in regional applications. For instance, upscaling maximum $\mathrm{CH}_{4}$ production potential $\left(\hat{P}_{\mathrm{CH}_{4}}\right)$ and maximum $\mathrm{CH}_{4}$ oxidation potential $\left(\hat{Q}_{\mathrm{CH}_{4}}\right)$ from the calibrated sites to a region is critical. Currently, we use the maximum monthly NPP derived from a 50-year historical TEM simulation to scale the parameter $\hat{P}_{\mathrm{CH}_{4}}$ and the maximum monthly soil respiration to scale the parameter $\hat{Q}_{\mathrm{CH}_{4}}$. Both NPP and soil respiration are simulated with TEM. The extrapolation is based on the fact that $\mathrm{CH}_{4}$ productivity is usually positively related with NPP (e.g. Chanton et al., 1995), and $\mathrm{CH}_{4}$ oxidation is positively related with respiration (e.g. Nakano et al., 2004). The scaling is based upon the vegetation cover data. The remaining model parameters derived from the calibrated site are used for our regional extrapolations. Thus, as a next step, we will test how different ways in extrapolating the sitespecific parameters to a region affect the uncertainties in the wetland $\mathrm{CH}_{4}$ emissions quantified with the $\mathrm{CH}_{4}$ models of different complexities. Also, an analysis of uncertainty due to equifinality will be attempted to investigate robustness of the parameterization from calibration at the limited number of sites (Tang and Zhuang, 2008).

The regional water table dynamics are another major source of uncertainty in quantifying regional wetland $\mathrm{CH}_{4}$ emissions. Standing water depth on top of soils is also essential to a proper quantification of regional $\mathrm{CH}_{4}$ effluxes. 
In particular, when the S4 model is used in regional simulations, there are grid cells, where vegetation is sparse, emitting $\mathrm{CH}_{4}$ mainly via ebullition. In contrast, the S1 and S2 models greatly underestimate the $\mathrm{CH}_{4}$ emissions in such cases (e.g. Fig. 10). In these simulations, water table depths play a significant role in affecting $\mathrm{CH}_{4}$ production, oxidation, soil pressure profile, and diffusion process. To more accurately simulate water table dynamics, we are currently testing several different algorithms (e.g. Granberg et al., 1999; Weiss et al., 2006). The methane models with different complexities will be further coupled with existing soil physics models (e.g. Zhuang et al., 2001, 2003; Tang and Zhuang, 2010) and with the tested water table depth model to conduct regional and global analyses of wetland $\mathrm{CH}_{4}$ emissions.

\section{Conclusions}

We revised an extant process-based biogeochemistry model, the Terrestrial Ecosystem Model to account for the effects of multiple substances in a soil profile on $\mathrm{CH}_{4}$ production, oxidation, and transport. The new development allows $\mathrm{CH}_{4}$ effluxes to be modeled with different levels of model complexity. When four-substances $\left(\mathrm{O}_{2}, \mathrm{~N}_{2}, \mathrm{CO}_{2}\right.$ and $\left.\mathrm{CH}_{4}\right)$ are considered, the inhibitory effect of $\mathrm{O}_{2}$ on $\mathrm{CH}_{4}$ production and the stimulatory effect of $\mathrm{O}_{2}$ on $\mathrm{CH}_{4}$ oxidation are well accounted for, and ebullition is modeled in a physically logical manner. When ebullition is modeled with a concentrationbased threshold approach and the inhibition effect of $\mathrm{O}_{2}$ on $\mathrm{CH}_{4}$ production, and the competition for $\mathrm{O}_{2}$ between methanotrophy and heterotrophic respiration are considered, the model becomes essentially a two-substance system. If we ignore the role of $\mathrm{O}_{2}$, while modeling bubble ebullition with the concentration-based threshold function, the model is reduced to a one-substance system. These models were tested through a group of sensitivity analyses at two temperate peatland sites in Michigan. We showed that only the foursubstance model with the new ebullition algorithm is able to account for the effects of a sudden drop in atmospheric pressure or in water table on episodic emissions. All models simulated the retardation of $\mathrm{CH}_{4}$ efflux after an increase in surface standing water due to inhibited diffusion and enhanced rhizospheric oxidation. We conclud that, to more accurately account for the effects of atmospheric pressure dynamics and water table dynamics on methane effluxes, the four-substance model with the probabilistic but physics-based ebullition algorithm should be used in the future to quantify global wetland $\mathrm{CH}_{4}$ emissions. Further, to more accurately simulate the pore water gas concentrations and different pathways of $\mathrm{CH}_{4}$ transport, an exponential root distribution function should be used and the phase-related parameters should be treated as temperature dependent.

\section{Appendix A}

The Henry's law constants (unit: $\mathrm{M} \mathrm{atm}^{-1}$ ) (Sander, 1999) are computed as

$$
\begin{aligned}
& H=6.1 \times 10^{-4} \exp \left[-1300\left(\frac{1}{T}-\frac{1}{298.0}\right)\right] \text { for } \mathrm{N}_{2} \\
& H=1.3 \times 10^{-3} \exp \left[-1500\left(\frac{1}{T}-\frac{1}{298.0}\right)\right] \text { for } \mathrm{O}_{2} \\
& H=3.4 \times 10^{-2} \exp \left[-2400\left(\frac{1}{T}-\frac{1}{298.0}\right)\right] \text { for } \mathrm{CO}_{2} \\
& H=1.3 \times 10^{-3} \exp \left[-1700\left(\frac{1}{T}-\frac{1}{298.0}\right)\right] \text { for } \mathrm{CH}_{4}
\end{aligned}
$$

where $T$ is temperature (unit: $\mathrm{K}$ ).

The Bunsen coefficient or solubility for gas $i$ is related to Henry's law constant as

$\alpha_{i}=H_{i} \times \frac{T}{12.2}$

The diffusivities (unit: $\mathrm{m}^{2} \mathrm{~s}^{-1}$ ) (Frank et al., 1996; Arah and Stephen, 1998; Winkelmann, 2008) in air are computed as

$$
\begin{aligned}
& D_{\mathrm{a}}=1.93 \times 10^{-5} \times\left(\frac{T}{273.0}\right)^{1.82} \text { for } \mathrm{N}_{2} \\
& D_{\mathrm{a}}=1.8 \times 10^{-5} \times\left(\frac{T}{273.0}\right)^{1.82} \text { for } \mathrm{O}_{2} \\
& D_{\mathrm{a}}=1.47 \times 10^{-5} \times\left(\frac{T}{273.15}\right)^{1.792} \text { for } \mathrm{CO}_{2} \\
& D_{\mathrm{a}}=1.9 \times 10^{-5} \times\left(\frac{T}{298.0}\right)^{1.82} \text { for } \mathrm{CH}_{4}
\end{aligned}
$$

The diffusivities (unit: $\mathrm{m}^{2} \mathrm{~s}^{-1}$ ) in water are computed as

$$
\begin{aligned}
& D_{\mathrm{w}}=2.57 \times 10^{-9} \times\left(\frac{T}{273.0}\right) \text { for } \mathrm{N}_{2} \\
& D_{\mathrm{w}}=2.4 \times 10^{-9}\left(\frac{T}{298.0}\right) \text { for } \mathrm{O}_{2} \\
& D_{\mathrm{w}}=1.81 \times 10^{-6} \exp \left(\frac{-2032.6}{T}\right) \text { for } \mathrm{CO}_{2} \\
& D_{\mathrm{w}}=1.5 \times 10^{-9} \times\left(\frac{T}{298.0}\right) \text { for } \mathrm{CH}_{4}
\end{aligned}
$$




\section{Appendix B}

The maximum $\mathrm{CH}_{4}$ production potential is defined as

$P_{\mathrm{CH}_{4}}^{*}=\hat{P}_{\mathrm{CH}_{4}} f\left(S_{\mathrm{OM}}(z, t)\right) f(T(z, t)) f(\mathrm{pH}(z, t)) f(E h(z, t))$

where $f\left(S_{\mathrm{OM}}(z, t)\right), f(T(z, t)), f(\mathrm{pH}(z, t)), f(E h(z, t))$ are multiplier functions of methanogenesis substrate availability (modeled as a function of scaled NPP), soil temperature, $\mathrm{pH}$ value and redox potential, as defined in Zhuang et al. (2004). $\hat{P}_{\mathrm{CH}_{4}}$ (unit: $\mathrm{mol} \mathrm{m}^{-3} \mathrm{~s}^{-1}$ ) is a scaling parameter for model calibration. Another site specific parameter that needs calibration is the $Q_{10}$ coefficient $\left(P_{Q_{10}}\right)$ of $f(T(z, t))$.

The maximum $\mathrm{CH}_{4}$ oxidation potential is defined as

$O_{\mathrm{CH}_{4}}^{*}=\hat{O}_{\mathrm{CH}_{4}} f(T(z, t)) f(\theta(z, t)) f(E h(z, t))$

where $f(T(z, t)), f(\theta(z, t)), f(E h(z, t))$ are functions of soil temperature, soil moisture and redox potential (see Zhuang et al., 2004 for detailed descriptions). Parameter $\hat{O}_{\mathrm{CH}_{4}}$ (unit: $\mathrm{mol} \mathrm{m}^{-3} \mathrm{~s}^{-1}$ ) is calibrated for every representative site. The $Q_{10}$ coefficient for temperature effect is set to 2 throughout this study.

\section{Appendix C}

For the diffusive flux, the diffusion constant in Eq. (1) is defined for the bulk medium, which is conventionally computed (Stephen et al., 1998) as

$D_{i}=\frac{1}{\tau} \frac{\epsilon D_{i, \mathrm{a}}+\alpha_{i} \theta D_{i, \mathrm{w}}}{\epsilon+\alpha_{i} \theta}$

where subscripts a and $\mathrm{w}$ denote the diffusivity in air and in water (see Appendix A for ways of computation). $\tau$ is the tortuosity factor in the soil, taken as 1.5 throughout the study (Arah and Stephen, 1998).

For gas transport through the aerenchyma of wetland plants, we, following the argument in other studies (Teal and Kanwisher, 1966; Matthews et al., 2000; Segers and Leffelaar, 2001), assumed the $\mathrm{N}_{2}, \mathrm{CO}_{2}$ and $\mathrm{CH}_{4}$ are transported in a similar way, such that

$R_{i}=R_{i}^{*}\left(y_{i, \mathrm{a}}-y_{i, \mathrm{~atm}}\right)=\lambda_{\mathrm{r}} L_{v} D_{i, \mathrm{a}} f(t)\left(y_{i, \mathrm{a}}-y_{i, \mathrm{~atm}}\right)$

where $\lambda_{\mathrm{r}}$ (unit: $\mathrm{m}$ air ( $\mathrm{m}$ root) $)^{-1}$ ) is the specific conductivity of the root system and $L_{v}$ (unit: $\mathrm{m}$ root $\mathrm{m}^{-3}$ soil) is the root length density. A value of $3.0 \times 10^{-4}$ was used for $\lambda_{\mathrm{r}}$. The vertical distribution of $L_{v}$ in soil is assumed following the Gale-Grigal model (Jackson et al., 1996) (see the exponential model in Appendix D). The temporal variation $f(t)$ of the root is modeled similarly to Zhuang et al. (2004) and Walter and Heimann (2000). Also, we assumed the four gases can either be transported from the atmosphere to the roots or from the roots to the atmosphere. When the onesubstance model is switched on, the oxidation of $\mathrm{CH}_{4}$ in the rhizosphere (Beckett et al., 2001) is not considered explicitly, rather, as in Walter and Heimann (2000), we assume 50\% of $\mathrm{CH}_{4}$ is oxidized.

In the $\mathrm{S} 4$ model, the governing equation for $\mathrm{CH}_{4}$ is

$$
\begin{aligned}
\frac{\partial y_{\mathrm{CH}_{4}}}{\partial t}= & \frac{\partial}{\partial z}\left(D_{\mathrm{CH}_{4}} \frac{\partial y_{\mathrm{CH}_{4}}}{\partial z}\right)+\frac{P_{\mathrm{CH}_{4}}^{*}}{1+\eta y_{\mathrm{O}_{2}, \mathrm{w}}} \\
& -Q_{\mathrm{CH}_{4}}^{*} \frac{y_{\mathrm{CH}_{4}, \mathrm{w}}}{k_{\mathrm{CH}_{4}}+y_{\mathrm{CH}_{4}, \mathrm{w}}} \frac{y_{\mathrm{O}_{2}, \mathrm{w}}}{k_{\mathrm{O}_{2}}+y_{\mathrm{O}_{2}, \mathrm{w}}} \\
& -E_{\mathrm{CH}_{4}}+R_{\mathrm{CH}_{4}}^{*}\left(y_{\mathrm{CH}_{4}, \mathrm{~atm}}-y_{\mathrm{CH}_{4}, \mathrm{a}}\right)
\end{aligned}
$$

for $\mathrm{CO}_{2}$ is

$$
\begin{aligned}
\frac{\partial y_{\mathrm{CO}_{2}}}{\partial t} & =\frac{\partial}{\partial z}\left(D_{\mathrm{CO}_{2}} \frac{\partial y_{\mathrm{CO}_{2}}}{\partial z}\right)+\frac{P_{\mathrm{CH}_{4}}^{*}}{1+\eta y_{\mathrm{O}_{2}, \mathrm{w}}} \\
& +Q_{\mathrm{CH}_{4}}^{*} \frac{y_{\mathrm{CH}_{4}, \mathrm{w}}}{k_{\mathrm{CH}_{4}}+y_{\mathrm{CH}_{4}, \mathrm{w}}} \frac{y_{\mathrm{O}_{2}, \mathrm{w}}}{k_{\mathrm{O}_{2}}+y_{\mathrm{O}_{2}, \mathrm{w}}} \\
& +V_{\mathrm{R}}^{*} \frac{y_{\mathrm{O}_{2}, \mathrm{w}}}{k_{\mathrm{R}}+y_{\mathrm{O}_{2}, \mathrm{w}}}-E_{\mathrm{CO}_{2}}+R_{\mathrm{CO}_{2}}^{*}\left(y_{\mathrm{CO}_{2}, \mathrm{~atm}}-y_{\mathrm{CO}_{2}, \mathrm{a}}\right)
\end{aligned}
$$

for $\mathrm{O}_{2}$ is

$$
\begin{aligned}
\frac{\partial y_{\mathrm{O}_{2}}}{\partial t} & =\frac{\partial}{\partial z}\left(D_{\mathrm{O}_{2}} \frac{\partial y_{\mathrm{O}_{2}}}{\partial z}\right)-2 Q_{\mathrm{CH}_{4}}^{*} \frac{y_{\mathrm{CH}_{4}, \mathrm{w}}}{k_{\mathrm{CH}_{4}}+y_{\mathrm{CH}_{4}, \mathrm{w}}} \frac{y_{\mathrm{O}_{2}, \mathrm{w}}}{k_{\mathrm{O}_{2}}+y_{\mathrm{O}_{2}, \mathrm{w}}} \\
& -V_{\mathrm{R}}^{*} \frac{y_{\mathrm{O}_{2}, \mathrm{w}}}{k_{\mathrm{R}}+y_{\mathrm{O}_{2}, \mathrm{w}}}-E_{\mathrm{O}_{2}}+R_{\mathrm{O}_{2}}^{*}\left(y_{\mathrm{O}_{2}, \mathrm{~atm}}-y_{\mathrm{O}_{2}, \mathrm{a}}\right)
\end{aligned}
$$

and for $\mathrm{N}_{2}$ is

$\frac{\partial y_{\mathrm{N}_{2}}}{\partial t}=\frac{\partial}{\partial z}\left(D_{\mathrm{N}_{2}} \frac{\partial y_{\mathrm{N}_{2}}}{\partial z}\right)-E_{\mathrm{N}_{2}}+R_{\mathrm{N}_{2}}^{*}\left(y_{\mathrm{N}_{2}, \mathrm{~atm}}-y_{\mathrm{N}_{2}, \mathrm{a}}\right)$

\section{Appendix D}

The root length density in Eq. (C2) is defined as

$L_{v}=R_{\mathrm{veg}} f(z)=-R_{\mathrm{veg}} \times 100 \log (\beta) \beta^{100 z}$

where $\beta$ is 0.943 for Buck Hollow Bog, and 0.910 for Big Cassandra Bog. $R_{\text {veg }}$ is a scaling parameter needed in calibration to account for differences in conducting capabilities for different plants. Note, the integrated root distribution function $f(z)$ from lower boundary to soil surface equals one. The alternative root distribution used in Sect. 3.4, is defined as

$f(z)=\begin{array}{ll}\frac{2}{R_{\mathrm{d}}}\left(1-\frac{z}{R_{\mathrm{d}}}\right) & \text { for } 0 \leq z \leq R_{\mathrm{d}} \\ 0 & \text { otherwise }\end{array}$

where $R_{\mathrm{d}}$ is root depth, computed using the Gale-Grigal model. This is different from the formula adopted in Walter and Heimann (2000) and Zhuang et al. (2004) in that we here imposed the constraint such that the vertical integration of $f(z)$ equals one. 


\begin{tabular}{|c|c|c|}
\hline Symbol & Definition & Unit \\
\hline$\alpha_{i}$ & Bunsen coefficient for substance $i$ & unitless \\
\hline$\beta$ & coefficient for root distribution & unitless \\
\hline$\delta(s)$ & Dirac delta function & unitless \\
\hline$\epsilon(z, t)$ & air-filled porosity & $\mathrm{m}^{3}$ air $\mathrm{m}^{-3}$ soil \\
\hline$\eta$ & inhibition coefficient of $\mathrm{O}_{2}$ on methanogenesis & $\mathrm{m}^{3}$ water $\mathrm{mol}^{-1}$ \\
\hline$\theta(z, t)$ & soil moisutre & $\mathrm{m}^{3}$ water $\mathrm{m}^{-3}$ soil \\
\hline$\lambda_{\mathrm{r}}$ & specific conductivity of the root system & $\mathrm{m}$ air $\mathrm{m}^{-1}$ root \\
\hline$\tau$ & tortuosity factor in the soil & unitless \\
\hline \multirow[t]{2}{*}{$b$} & pressure imposed by water column above water table $\left(z_{\mathrm{wt}}<0\right)$ & \\
\hline & or soil surface $\left(z_{\mathrm{wt}} \geq 0\right)$ & $\mathrm{m}$ \\
\hline $\mathrm{CH}_{4, \max }$ & threshold concentration for $\mathrm{CH}_{4}$ ebullition & $\mathrm{mol} \mathrm{m}^{-3}$ water \\
\hline$D_{i}$ & bulk diffusivity of substance $i$ in soil & $\mathrm{m}^{2} \mathrm{~s}^{-1}$ \\
\hline$D_{i, \mathrm{a}}$ & diffusivity of substance $i$ in air & $\mathrm{m}^{2} \mathrm{~s}^{-1}$ \\
\hline$D_{i, \mathrm{w}}$ & diffusivity of substance $i$ in water & $\mathrm{m}^{2} \mathrm{~s}^{-1}$ \\
\hline$E(z)$ & total ebullition of the gases at depth $z$ & $\mathrm{~mol} \mathrm{~m}^{-2}$ \\
\hline$E b_{i}(z)$ & potential ebullition of gas $i$ at depth $z$ & $\mathrm{~mol} \mathrm{~m}^{-2}$ \\
\hline$H_{i}$ & Henry's law constant for substance $i$ & $\mathrm{M} \mathrm{atm}^{-1}$ \\
\hline$k_{\mathrm{CH}_{4}}$ & Michaelis-Menten coefficient for $\mathrm{CH}_{4}$ & $\mathrm{~mol} \mathrm{~m}^{-3}$ water \\
\hline$k_{\mathrm{O}_{2}}$ & Michaelis-Menten coefficient for $\mathrm{O}_{2}$ & $\mathrm{~mol} \mathrm{~m}^{-3}$ water \\
\hline$k_{\mathrm{R}}$ & Michaelis-Menten coefficient for respiration & $\mathrm{mol} \mathrm{m}^{-3}$ water \\
\hline$L_{v}$ & root length density & $\mathrm{m}$ root $\mathrm{m}^{-3}$ soil \\
\hline $\mathrm{O}_{2, \max }$ & threshold concentration for $\mathrm{O}_{2}$ ebullition & $\mathrm{mol} \mathrm{m}^{-3}$ water \\
\hline$p$ & atmospheric pressure & $\mathrm{Pa}$ \\
\hline$P_{\mathrm{CH}_{4}}^{*}$ & maximum $\mathrm{CH}_{4}$ production potential & $\mathrm{mol} \mathrm{m}^{-3} \mathrm{~s}^{-1}$ \\
\hline$\hat{P}_{\mathrm{CH}_{4}}$ & scaling parameter for $P_{\mathrm{CH}}^{*}$ & $\mathrm{~mol} \mathrm{~m}^{-3} \mathrm{~s}^{-1}$ \\
\hline$P_{\mathrm{OX}}$ & fraction of $\mathrm{CH}_{4}$ oxidized in rhizosphere & unitless \\
\hline$P_{Q_{10}}$ & $Q_{10}$ coefficient for methanogenesis & unitless \\
\hline$p_{\mathrm{r}}$ & probability of bubble redissolution & unitless \\
\hline$P_{S}(z, t)$ & total gas pressure at depth $z$, time $t$ & $\mathrm{~Pa}$ \\
\hline$P_{s, i}(z, t)$ & partial gas pressure at depth $z$, time $t$ by substance $i$ & $\mathrm{~Pa}$ \\
\hline$P_{0}$ & pressure scaling factor & $\mathrm{Pa}$ \\
\hline$\hat{p}$ & scaled atmospheric pressure & unitless \\
\hline$Q_{\mathrm{CH}_{4}}^{*}$ & maximum $\mathrm{CH}_{4}$ oxidation potential & $\mathrm{mol} \mathrm{m}^{-3} \mathrm{~s}^{-1}$ \\
\hline$\hat{Q}_{\mathrm{CH}_{4}}$ & scaling parameter for $Q_{\mathrm{CH}_{4}}^{*}$ & $\mathrm{~mol} \mathrm{~m}^{-3} \mathrm{~s}^{-1}$ \\
\hline$R_{i}^{*}$ & scaled rate of plant aided transport & $\mathrm{s}^{-1}$ \\
\hline$R_{\mathrm{d}}$ & root depth & $\mathrm{m}$ \\
\hline$R_{\mathrm{veg}}$ & $\begin{array}{l}\text { vegetation type dependent scaling parameter of gas conducting } \\
\text { capability }\end{array}$ & unitless \\
\hline$V_{\mathrm{R}}^{*}$ & maximum rate of respiration & $\mathrm{mol} \mathrm{m}^{-3} \mathrm{~s}^{-1}$ \\
\hline$y_{i}$ & bulk concentration of substance $i$ & $\mathrm{~mol} \mathrm{~m}^{-3}$ \\
\hline$y_{i, \mathrm{a}}$ & gaseous concentration of substance $i$ & $\mathrm{~mol} \mathrm{~m}^{-3}$ air \\
\hline$y_{i, \mathrm{w}}$ & aqueous concentration of substance $i$ & $\mathrm{~mol} \mathrm{~m}^{-3}$ water \\
\hline$y_{i, \text { atm }}$ & concentration of substance $i$ in the atmosphere & $\mathrm{mol} \mathrm{m}^{-3}$ air \\
\hline & equilibrium bulk concentration of substance $i$ & $\mathrm{~mol} \mathrm{~m}^{-3}$ \\
\hline$\tilde{y}_{i, \mathrm{w}}$ & equilibrium aqueous concentration of substance $i$ & $\mathrm{~mol} \mathrm{~m}^{-3}$ water \\
\hline$z_{\mathrm{wt}}$ & depth of water table & $\mathrm{m}$ \\
\hline$z_{\mathrm{s}}$ & depth of soil surface & $\mathrm{m}$ \\
\hline$z_{0}$ & water depth scaling factor & $\mathrm{m}$ \\
\hline$Z_{\text {soil }}$ & depth of lower boundary & $\mathrm{m}$ \\
\hline
\end{tabular}


Acknowledgements. J. Tang is supported with graduate fellowships from the Purdue Climate Change Research Center and the NASA Earth System Science program. The study is in part supported by the Department of Energy (Abrupt Climate Change program) and the National Science Foundation (projects ARC-0554811 and EAR-0630319). The study is also a contribution of the Methane Working Group of the National Center for Ecological Analysis and Synthesis (NCEAS). Comments from two anonymous reviewers and the editor greatly helped to improve the early version of this manuscript.

Edited by: A. Arneth

\section{References}

Arah, J. R. M. and Kirk, G. J. D.: Modeling rice plant-mediated methane emission, Nutr. Cycl. Agroecosys., 58, 221-230, 2000.

Arah, J. R. M. and Stephen, K. D.: A model of the processes leading to methane emission from peatland, Atmos. Environ., 32, 32573264, 1998.

Baird, A. J., Beckwith, C. W., Waldron, S., and Waddington, J. M.: Ebullition of methane-containing gas bubbles from near-surface Sphagnum peat, Geophys. Res. Lett., 31, L21505, doi:10.1029/2004GL021157, 2004.

Bazhin, N. M.: Gas transport in a residual layer of a water basin, Chemosphere-Global Change Science, 3, 33-40, 2001.

Bazhin, N. M.: Influence of plants on the methane emission from sediments, Chemosphere, 54, 209-215, 2004.

Beckett, P. M., Armstrong, W., and Armstrong, J.: Mathematical modeling of methane transport by Phragmites: the potential for diffusion within the roots and rhizosphere, Aquat. Bot., 69, 293312, 2001.

Cao, M., Dent, J. B., and Heal, O. W.: Modeling methane emissions from rice paddies, Global Biogeochem. Cy., 9, 183-195, 1995.

Chanton, J. P., Bauer, J. E., Glaser, P. A., Siegel, D. E., Kelley, C. A., Tyler, S. C., Romanowicz, E. H., and Lazrus, A.: Radiocarbon evidence for the substrates supporting methane formation within northern Minnesota peatlands, Geochim. Cosmochim. Ac., 59, 3663-3668, 1995.

Conrad, R.: Control of Methane Production in Terrestrial Ecosystems, J. Wiley \& Sons, New York, NY, USA, 1989.

Coulthard, T. J., Baird, A. J., Ramirez, J., and Waddington, J. M.: Methane Dynamics in Peat: Importance of Shallow Peats and a Novel Reduced-Complexity Approach for Modeling Ebullition, AGU, Washington, DC, USA, 2009.

Denman, K., Brasseur, G., Chidthaisong, A., Ciais, P., Cox, P., Dickinson, R. E., Hauglustaine, D., Heinze, C., Holland, E., Jacob, D., Lohmann, U., Ramachandran, S., da Silva Dias, P. L., Wofsy, S. C., and Zhang, X.: Coupling between changes in the climate system and biogeochemistry, in: Climate Change 2007: The Physical Science Basis. Contribution of Working Group I to the Fourth Assessment Report of the Intergovernmental Panel on Climate Change, edited by: Solomon, S., Qin, D., Manning, M., Chen, Z., Marguis, M., Avery, K., Tignor, M., and Hiller, M., Cambridge University Press, UK and New York, NY, USA, 2007.

Forster, P., Ramaswamy, V., Artaxo, P., Berntsen, T., Betts, R., Fahey, D., Haywood, J., Lean, J., Lowe, D., Myhre, G., Nganga, J., Prinn, R., Raga, G., Schulz, M., and Dorland, R. V.: Changes in atmospheric constituents and in radiative forcing, in: Cli- mate Change 2007: The Physical Science Basis. Contribution of Working Group I to the Fourth Assessment Report of the Intergovernmental Panel on Climate Change, edited by: Solomon, S., Qin, D., Manning, M., Chen, Z., Marguis, M., Avery, K., Tignor, M., and Hiller, M., Cambridge University Press, UK and New York, NY, USA, 2007.

Frank, M. J. W., Kuipers, J. A. M., and van Swaaij, W. P. M.: Diffusion coefficients and viscosities of $\mathrm{CO}_{2}+\mathrm{H}_{2} \mathrm{O}, \mathrm{CO}_{2}+\mathrm{CH}_{3} \mathrm{OH}$, $\mathrm{NH}_{3}+\mathrm{H}_{2} \mathrm{O}$ and $\mathrm{NH}_{3}+\mathrm{CH}_{3} \mathrm{OH}$ liquid mixtures, J. Chem. Eng. Data, 41, 297-302, 1996.

Granberg, G., Grip, H., Löfvenius, M. O., Sundh, I., Svensson, B. H., and Nilsson, M.: A simple model for simulation of water content, soil frost, and soil temperatures in boreal mixed mires, Water Resour. Res., 35, 3771-3782, doi:10.1029/1999WR900216, 1999.

Granberg, G., Ottosson-Lfvenius, M., Grip, H., Sundh, I., and Nilsson, M.: Effect of climatic variability from 1980 to 1997 on simulated methane emission from a boreal mixed mire in northern Sweden, Global Biogeochem. Cy., 15, 977-991, doi:10.1029/2000GB001356, 2001.

Houweling, S., Kaminski, T., Dentener, F., Lelieveld, J., and Heimann, M.: Inverse modeling of methane sources and sinks using the adjoint of a global transport model, J. Geophys. Res., 104, 26137-26160, doi:10.1029/1999JD900428, 1999.

Jackson, R. B., Canadell, J., Ehleringer, J. R., Mooney, H. A., Sala, O. E., and Schulze, E. D.: A global analysis of root distributions for terrestrial biomes, Oecologia, 108, 389-411, 1996.

Jauhiainen, J. I., Takahashi, H., Heikkinen, J. E. P., Martikainen, P. J., and Vasander, H.: Carbon fluxes from a tropical peat swamp forest floor, Glob. Change Biol., 11, 1788-1797, doi:10.1111/j.1365-2486.2005.001031.x, 2005.

Kellner, E., Baird, A. J., Oosterwoud, M., Harrison, K., and Waddington, J. M.: Effect of temperature and atmospheric pressure on methane $\left(\mathrm{CH}_{4}\right)$ ebullition from near-surface peats, Geophys. Res. Lett., 33, L18405, doi:10.1029/2006GL027509, 2006.

Martens, C. and Klump, J. V.: Biogeochemical cycling in an organic-rich coastal marine basin-1. Methane sediment-water exchange processes, Geochim. Cosmochim. Ac., 44, 471-490, 1980.

Matthews, R. B., Wassmann, R., and Arah, J.: Using a crop/soil simulation model and GIS techniques to assess methane emissions from rice fields in Asia. I. Model development, Nutr. Cycl. Agroecosys., 58, 141-159, 2000.

Mattson, M. D. and Likens, G. E.: Air pressure and methane fluxes, Nature, 347, 718-719, 1990.

Mitchell, T. D., Carter, T. R., Jones, P. D., Hulme, M., and New, M.: A comprehensive set of high-resolution grids of monthly climate for Europe and the globe: the observed record (1901-2000) and 16 scenarios (2001-2100), Tyndall Center Working Paper 55, University of East Anglia, Norwich, UK, July, 25 pp., 2004.

Nakano, T., Inoue, G., and Fukuda, M.: Methane consumption and soil respiration by a birch forest soil in West Siberia, Tellus B, 56, 223-229, doi:10.1111/j.1600-0889.2004.00102.x, 2004.

Oleson, K. W., Dai, Y., Bonan, G., Bosilovich, M., Dickinson, R., Dirmeyer, P., Hoffman, F., Houser, P., Levis, S., Niu, G., Thornton, P., Vertenstein, M., Yang, Z., and Zeng, X.: Technical description of he community land model (CLM), Tech. rep., Terrestrial Science Section, Climate and Global Dynamics Division, National Center for Atmospheric Research, Boulder, Colorado, 
USA, 2004.

Peck, A. J.: The water table as affected by atmospheric pressure, J. Geophys. Res., 65, 2383-2388, 1960.

Potter, C. S.: An ecosystem simulation model for methane production and emission from wetlands, Global Biogeochem. Cy., 11, 495-506, 1997.

Rosenberry, D. O., Glaser, P. H., Siegel, D. I., and Weeks, E. P.: Use of hydraulic head to estimate volumetric gas content and ebullition flux in northern peatlands, Water Resour. Res., 39, 1066, doi:10.1029/2002WR001377, 2003.

Rothfuss, F. and Conrad, R.: Effect of gas bubbles on the diffusive flux of methane in anoxic paddy soil, Limnol. Oceanogr., 43, 1511-1518, 1998.

Sander, R.: Compilation of Henry's law constants for inorganic and organic species of potential importance in environmental chemistry (version 3), http://www.mpch-mainz.mpg.de/ sander/res/ henry.html, 1999

Sass, R. L., Fisher Jr., M. F., and Huang, Y.: A process-based model for methane emissions from irrigated rice fields: experimental basis and assumptions, Nutr. Cycl. Agroecosys., 58, 249-258, 2000.

Schiesser, W. E.: The Numerical Method of Lines: Integration of Partial Differential Equations, Academic Press, San Diego, 1991.

Segers, R. and Leffelaar, P. A.: Modeling methane fluxes in wetlands with gas-transporting plants, 1. Single-root scale, J. Geophys. Res., 106, 3511-3528, 2001.

Shannon, R. D. and White, J. R.: A three-year study of controls on methane emissions from two Michigan peatlands, Biogeochemistry, 27, 35-60, 1994.

Shannon, R. D., White, J. R., Lawson, J. E., and Gilmour, B. S.: Methane efflux from emergent vegetation in peatlands, J. Ecol., 84, 239-246, 1996.

Stephen, K. D., Arah, J. R. M., Daulat, W., and Clymo, R. S.: Rootmediated gas transport in peat determined by argon diffusion, Soil Biol. Biochem., 30, 501-508, 1998.

Tang, J. and Zhuang, Q.: Equifinality in parameterization of process-based biogeochemistry models: A significant uncertainty source to the estimation of regional carbon dynamics, J. Geophys. Res., 113, G04010, doi:10.1029/2008JG000757, 2008.

Tang, J. and Zhuang, Q.: Modeling soil thermal and hydrological dynamics and changes of growing season in Alaskan terrestrial ecosystems, Clim. Change, accepted, 2010.

Teal, J. M. and Kanwisher, J. W.: Gas transport in the marsh grass, Spartina alterniflora, J. Exp. Bot., 17, 355-361, 1966.

Tokida, T., Miyazaki, T., and Mizoguchi, M.: Ebullition of methane from peat with falling atmospheric pressure, Geophys. Res. Lett., 32, L13823, doi:10.1029/2005GL022949, 2005.

Tokida, T., Miyazaki, T., Mizoguchi, M., Nagata, O., Takakai, F., Kagemoto, A., and Hatano, R.: Falling atmospheric pressure as a trigger for methane ebullition from peatland, Global Biogeochem. Cy., 21, GB2003, doi:10.1029/2006GB002790, 2007.

van Bodegom, P., Goudriaan, J., and Leffelaar, P.: A mechanistic model on methane oxidation in a rice rhizosphere, Biogeochemistry, $55,145-177,2001$. van Huissteden, J., van den Bos, R., and Alvarez, I. M.: Modeling the effect of water table management on $\mathrm{CO}_{2}$ and $\mathrm{CH}_{4}$ from peat soils, Neth. J. Geosci., 85, 3-18, 2006.

Wallace, J. M. and Hobbs, P. V.: Atmospheric Science, An Introductory Survey, Second Edition, Academic Press, San Diego, 2006.

Walter, B. P. and Heimann, M.: A process-based, climate-sensitive model to derive methane emissions from natural wetlands: application to five wetland sites, sensitivity to model parameters, and climate, Global Biogeochem. Cy., 14, 745-765, 2000.

Walter, B. P., Heimann, M., and Matthews, E.: Modeling modern methane emissions from natural wetlands, 1 . Model description and results, J. Geophys. Res., 106, 34189-34206, 2001.

Wania, R., Ross, I., and Prentice, I. C.: Implementation and evaluation of a new methane model within a dynamic global vegetation model: LPJ-WHyMe v1.3.1, Geosci. Model Dev., 3, 565-584, doi:10.5194/gmd-3-565-2010, 2010.

Weiss, R., Shurpali, N. J, Sallantaus, T., Laiho, R., Laine, J., and Alm, J.: Simulation of water table level and peat temperatures in boreal peatlands, Ecol. Model., 192, 441-456, 2006.

Winkelmann, J.: Diffusion of carbon dioxide(1); water(2); sodium chloride(3), in: Gases in Gases, Liquids and their Mixtures, edited by: Lechner, M., Springer, Berlin Heidelberg, 2273-2274, 2008.

Zhang, Y., Li, C., Trettin, C. C., Li, H., and Sun, G.: An integrated model of soil, hydrology, and vegetation for carbon dynamics in wetland ecosystems, Global Biogeochem. Cy., 16, 1061, doi:10.1029/2001GB001838, 2002.

Zhuang, Q., Romanovsky, V. E., and McGuire, A. D.: Incorporation of a permafrost model into a large-scale ecosystem model: Evaluation of temporal and spatial scaling issues in simulating soil thermal dynamics, J. Geophys. Res., 106, 33649-33670, 2001.

Zhuang, Q., McGuire, A. D., Melillo, J. M., Clein, J. S., Dargaville, R. J., Kicklighter, D. W., Myneni, R. B., Dong, J., Romanovsky, V. E., Harden, J., and Hobbie, J. E.: Carbon cycling in extratropical terrestrial ecosystems of the Northern Hemisphere during the 20th Century: A modeling analysis of the influences of soil thermal dynamics, Tellus, 55B, 751-776, 2003.

Zhuang, Q., Mellilo, J. M., Kicklighter, D. W., Prinn, R. G., McGuire, A. D., Steudler, P. A., Felzer, B. S., and Hu, S.: Methane fluxes between terrestrial ecosystems and the atmosphere at northern high latitudes during the past century: a retrospective analysis with a process-based biogeochemistry model, Global Biogeochem. Cy., 18, GB3010, doi:10.1029/2004GB002239, 2004.

Zhuang, Q., Melack, J. M., Zimov, S., Walter, K. M., Butenhoff, C. L., and Khalil, M. A. K.: Global methane emissions from wetlands, rice paddies and lakes, EOS T. Am. Geophys. Un., 90(5), 37-38, 2009.

Zona, D., Oechel, W. C., Kochendorter, J., Paw, U. K. T., Salyuk, A. N., Olivas, P. C., Oberbauer, S. F., and Lipson, D. A.: Methane fluxes during the initiation of a largescale water table manipulation experiment in the Alaskan Arctic tundra, Global Biogeochem. Cy., 23, GB2013, doi:10.1029/2009GB003487, 2009. 